\title{
Ueber einige quantitative Verhältnisse bei der Pepsinverdauung.
}

\author{
Nach Versuchen \\ von \\ Docent E. Schütz und Professor Iuppert.
}

Mitgetheilt von Huppért.

Die Untersuchung, deren Ergebnisse hier mitgetheilt werden, latte sich die Aufgabe gesetzt, das Verhältniss zu ermitteln, in welchem die Mengen der sich innerbalb eines gewissen Zeitabschnittes bildenden einzelnen Verdauungsproducte von den Versuchsbedingungen abhängen, oder mit anderen Worten, es sollte die Geschwindigkeit bestimmt werlen, mit welcher die einzelnen Verdauungsproducte unter verschiedenen Bedingungen entstehen. Auf diese Weise war die Erkennung von Gesetzmässigkeiten des Processes, und, abgesehen von rein quantitativen Verhältnissen, ein tieferer Einblick in das Wesen desselben zu erwarten. Wenn sich diese Erwartung bis zu einem gewissen Grade erfullte, so lag das einmal an der Anwendung der quantitativen Methode, da quantitative Untersuchungen immer mehr leisten als bloss qualitative, und ferner an dem Umstand, dass wir die Verdauungsproducte möglichst von einander trennten und nicht mehrere ungleichartige zugleich mit einander bestimmten.

Ihren Ausgang nahm die Untersuchung von dem von Schütz gehegten Wunsch, ein verlässliches Maass für die relativen Mengen des Pepsins ausfindig zu machen. Zu diesem Zweck zunächst hat $\mathrm{Schütz}$ diese mühevollen und zeitraubenden systematischen Untersuchungen ausgeführt. Die gesammten von ihm dabei erlangten Resultate sind in den folgenden grossen Tabellen enthalten. Den ihn vorwiegend interessirenden Theil, nämlich das Gesetz, nach welchem die Geschwindigkeit der "Pepton“bildung von der relativen 
Menge des Pepsins abhängt, hat $S c h u ̈ z^{3}$ ) in einer freilich von $\mathrm{Maly}^{2}$ ) arg missverstandenen Abhandlung bereits veröffentlicht.

Schütz hat die Arbeit im Jahre 1881 begonnen, und aus diesem frühen Datum erklärt sich nicht bloss der von Schütz gebrauchte Ausdruck "Pepton", mit dem das damals allein bekannte Brücke'sche Pepton gemeint war, sondern auch einzelnes Andere. So hat Schütz den Stickstoff der einen Albumose nach D u mas bestimmt, während man jetzt dazu bequemer das damals noch unbekannte Verfahren von $\mathrm{Kjeldahl}$ anwenden würde. Aus derselben Ursache hielten wir das amorphe Ovalbumin für reines Albumin und waren über seinen Gehalt an Mucoid in Unkenntniss, ein Uebelstand, welcher zwar die Untersuchung etwas erschwerte, aber auf das Resultat ohne störenden Einfluss war.

In der Folgezeit, und namentlich nach der Uebersiedelung von Schütz nach Wien, habe ich allein, aber im Einverständniss mit ihm, die von $S \operatorname{chütz}$ aufgefundenen Thatsachen ergänzt und näher $\mathrm{zu}$ begründen gesucht, wobei mir namentlich daran gelegen war, die gefundenen empirischen Geschwindigkeiten auf eine Differentialgleichung zurückzuführen. Es hätte sich so ein Verständniss für die empirischen Regeln eröffnet. Diese Bemühungen haben die späte Veröffentlichung der Untersuchung von Schütz verschuldet. Ich ziehe vor, was ich über den theoretischen Tbeil zu sagen habe, gesondert mitzutheilen, wozu mir hoffentlich noch Gelegenheit geboten sein wird. Aber auch ohne die theoretische Begründung werden die aufgefundenen Thatsachen Einiges bringen, was der Beachtung nicht unwerth sein dürfte.

Die Abhandlung zerfällt in folgende Abschnitte.

I. Das bei den Verdauungsversuchen befolgte Verfahren.

II. Die Ergebnisse der Verdauungsversuche.

III. Der genetische Zusammenhang der Erscheinungen.

IV. Die Bestimmung der relativen Pepsinmenge.

\section{Das bei den Verdaungsversuchen befolgte Verfahren.}

Zum leichteren Verständniss erscheint es vortheilhaft, vor der ausführlichen Darstellung der Trennungs- und Bestimmungsweisen

1) E. Schütz, Zeitschr. f. physiolog. Chemie Bd. 7 S. 577.1885.

2) Maly, dessen Jahresbericht Bd. 15 S. 266. 
anzugeben, welche Bestandtheile der Verdauungsmischung quantitativ bestimmt wurden, und wie wir dabei im Allgemeinen verfahren sind.

Aus der Flüssigkeit wurde zunächst das Acidalbumin durch Abstumpfen der freien Säure bis zu schwach saurer Reaction abgeschieden und aus dem Filtrat das in Lösung gebliebene Albumin durch Kochen gefällt. Das darauf gewonnene Filtrat wurde nach dem Hofmeister'schen Verfahren bei neutraler Reaction mit überschüssigem Ferriacetat gekocht und so die primäre Albumose niedergeschlagen; diese Fällung galt als gelungen, wenn eine Probe durch Ferrocyanwasserstoff auch nach längerer Zeit nicht im Geringsten getrübt wurde; aus dem Stickstoffgehalt des Niederschlags wurde die Menge der primären Albumose berechnet. Dieser primären Albumose ist das Mucoid beigemengt, und es musste darnach der Werth für die Albumose corrigirt werden, was ohne Schwierigkeit möglich war. Der noch in Lösung gebliebene Eiweisskörper wurde als Pepton im Sinne von Brücke angesehen und polarimetrisch bestimmt. Neumeister sowie H of meister ${ }^{1}$ ) sind übereinstimmend zu der Ansicht gekommen, dass das Brücke'sche Pepton wesentlich aus Beuteroalbumose besteht. Nach meiner Erfahrung wird die neutrale Lösung der Substanz durch Kupfersulfat nicht getrübt. Dieser Theil der Verdaungsproducte wird von uns als seeundäre Albumose angeführt.

Unser Product war aber noch verunreinigt durch das sog. eigentliche Pepton, das Pepton Kühne's. Wurde eine neutrale, aber viel Natriumacetat enthaltende Lösung des Brücke'schen Peptons mit Ammonsulfat vollständig gesättigt, so blieb noch eine die Biuretreaction gebende Substanz in Lösung. Diese Reaction braucht aber nicht durch echtes Pepton, oder wenigstens nicht von ihm allein, bedingt zu sein, denn es konnte die Vollständigkeit der Fällung der Albumose möglicher Weise durch die grosse Menge des von der Abscheidung der primären Albumose herrührenden Natriumacetats beeinträchtigt sein. Aber abgesehen hiervon war die Biuretfärbung auch bei längerer Dauer der Verdauung in den von mir untersuchten Fällen immer nur schwach. Auf eine gesonderte Bestimmung des Kühne'schen Peptons haben wir nicht eingehen können, weil das Trennungsverfahren durch Ammonsulfat damals

1) B. Neumeister, Zeitschr. f. Biologie Bd. 26 S. 339 . 1890. - F. H ofmeister, Zeitschr. f. analyt. Chemie Bd. 30 S. 110. 1891. 
noch nicht bekannt war. Die geringe Verunreinigung der secundären Albumose durch das Kühne'sche Pepton muss mit in den Kauf genommen werden.

Besonderen Werth haben wir auf die Beschaffenheit des A usgangsmaterials gelegt. Der Eiweisskörper, welcher zu den Versuchen dienen sollte, durfte keine säurebindenden Salze enthalten, sollte in gelöster Form verwendet werden und vor Allem epne einheitliche Substanz darstellen. Nur unter diesen Bedingungen waren unter einander vergleichbare Resultate $\mathrm{zu}$ gewärtigen. Ein Gehalt an säurebindenden Salzen hätte die Versuche über den Einfluss der Säureconcentration auf den Gang der Verdauung mindestens schwer beeinträchtigt. In Lösung sollte sich der Eiweisskörper befinden, weil sich nur so die zu den Versuchen gewählten Mengen genau dosiren lassen, was bei Anwendung von festem Eiweiss wenigstens nicht in dem gleichen Grade zu erreichen ist. Ein in Lösung befindlicher (ein homogenes System bildender) Eiweisskörper wird von der Verdauungsflüssigkeit in seiner ganzen Masse gleichnässig angegriffen und bietet den Reagentien nicht die unberechenbaren ungleichartigen Widerstände dar wie ein festes Stück Eiweiss. Die Einheitlichkeit der Substanz war ein Erforderniss, weil nicht vorauszusetzen war, dass verschiedene Eiweisskörper in gleichmässiger Weise verdaut werden, und natürliche Gemische mehrerer Eiweisskörper ihre Bestandtheile entweder nachweislich nicht in constantem Verhältniss enthalten, wie das Blutserum, oder deren constante Zusammensetzung, wie beim Eiereiweiss, nicht verbürgt und nicht wahrscheinlich ist.

Diesen Anforderungen entsprach nach dem Stand unserer Kenntnisse im Beginn der Untersuchung das durch Salze vom Globulin befreite Eiereiweiss. Die Entdeckung des Mucoids in demselben machte die eine Voraussetzung hinfällig, und es fragt sich nun, wie sich diese Thatsache in unsere Untersuchung einfügt. Zweierlei Beobachtungen geben hierüber Aufschluss. Das Ovomucoid wird bei der Pepsinverdaunng nicht verändert, und das Ovomucoid wird beim Kochen mit Ferriacetat in neutraler Lösung vollständig niedergeschlagen.

Es wurden $92 \mathrm{ccm}$ einer wässrigen Lösung von $0,7 \mathrm{~g}$ Ovomucoid, welches durch wiederholtes Fállen mit Alkohol vom Zucker befreit worden war, durch Zusatz von Salzsäure auf den Sauregehalt von $0,25 \%$ gebracht und mit $0,5 \mathrm{ccm}$ einer kräftigen Lösung reinen Pepsins vermischt. Unmittelbar.'nach 
der Herstellung der Losung ergab die polarimetrische Untersuchung eine Drehung von $-0,455^{\circ}$. Nachdem die Flüssigkeit 16 Stunden auf $30-35^{\circ}$ erwarmt worden war, besass die Losung genau dieselbe Drehung wie vorher. Die Flüssigkeit gab noch eine schone Biuretreaction ron demselben Farbenton, wie das Ovomucoid selbst, reducirte alkalische Kupferhydratlösung nicht, gab nach Zusatz von Natriumacetat mit Ferrocyankalium keinen Niederschlag; und durch Kochen mit essigsaurem Eisen bei neutraler Reaction liess sich der in Lösung befindliche Eiweisskórper, entsprechend dem unten mitgetheilten Verhalten des Mucoids, vollständig ausfällen. Das Filtrat von diesem Niederschlag gab keine Biuretreaction mehr. Bei der unter günstigen Verbaltnissen vorgenommenen Verdaung hatte also das Oromucoid keine Veränderung erlitten.

Nach C. Th. Mórner ${ }^{1}$ ) wird das Ovomucoid in der Kälte weder durch saures, noch durch neutralisirtes Eisenchlorid gefällt. Im Gegensatz hierzu wird es aber durch Kochen mit Ferriacetat bei neutraler Reaction vollständig niedergeschlagen, wie folgende Versuche ergeben.

Aus Eiereiweiss lassen sich auf diese Weise alle Eiweisskörper entfernen, das Filtrat enthält nur Zucker, gibt aber, auch nach der Concentration in der Wärme, die Biuretreaction nicht mehr.

Das Ovomucoid aus dem Eiweiss mehrerer Eier wurde zur Entfernung des Zuckers zweimal mit Alkohol gefällt, die wássrige Lösung durch Kochen vom Alkohol befreit, mit einem halben Eiereiweiss vermischt und der Behandlung mit Ferriacetat unterworfen. Im Filtrat war auch nach dem Eindampfen keine spur einer Biuretfarbung wahrzunehmen. Der Eisenniederschlag wurde darauf mit verdunnter Natronlauge aufgekocht. Das Filtrat gab die Biuretreaction, aber auch zugleich die Heller'sche Eiweissprobe. Es wurde mit 0,1 Volumen concentrirter Salzsaure längere Zeit im Wasserbad erwármt, wobei sich Flocken ausschieden; darauf reducirte die Flüssigkeit alkalische Kupferhydratlösung. Das durch das Eisensalz aus der Lósung entfernte Oromucoid war sonach als solches im Eisenniederschlag nachweisbar.

Ein gleicher Versuch wurde noch mit Ovomucoid (aus dem Eiweiss eines Eies) allein angestellt. Der Versuch war hier insofern schwieriger wie bei gleichzeitiger Gegenwart von Albumin, weil das Merkmal fur die gelungene Fällung, das Ausbleiben der Probe mit Ferrocyanwasserstoff fehlte. Ich konnte mich daher nur darnach richten, dass die Flüssigkeit nach dem Kochen amphotere Reaction besass. Auch hier gab das Filtrat, auch nach dem Eindampfen auf ein kleines Volumen, die Biuretreaction nicht.

In Bezug auf die Fállbarkeit des Ovomucoids nach dem „Verfahren von Schmidt-Milheim" ist Matthes ${ }^{2}$ ) zu dem gleichen Resultate gelangt wie ich.

Die Leichtigkeit, mit welcher das Ovomucoid nach dem von uns befolgten Verfahren aus seinen Lösungen entfernt werden kann,

1) C. Th. Mörner, Zeitschr. f. physiol. Chemie Bd. 18 S. 528.1898.

2) M. Matthes, Berliner klin. Wochenschr. Bd. 31 S. 532.1894. 
schliesst den Verdacht aus, dass ein Theil desselben noch der secundären Albumose beigemengt und mit ihr bestimmt worden sei. Dagegen ist das Mucoid zugleich mit der primären Albumose gefällt und mit ihr bestimmt worden. Die dabei erhaltenen Werthe bedürfen einer Correctur, und um diese ausführen zu können, müsste man wissen, wieviel in dem verwendeten Ovalbumin Mucoid enthalten war. Hierüber geben die folgenden Darlegungen befriedigende Auskunft.

Schüt hat die Albuminmenge, welche er zu seinen Versuchen verwendete, im Verlauf des bereits im Gange befindlichen Versuchs in der Mehrzabl der Fälle gewichtsanalytisch bestimmt. Um aber einen Anbalt für die Menge Eiweiss zu besitzen, welche zu den Versuchen genommen werden sollte, wurde der Gehalt der Lösung an Eiweiss einige Male auch polarimetrisch ermittelt. Dahei stellte sich heraus, dass die gewogene Menge immer erheblich geringer war als die durch die Polarisation bestimmte, und wenn man aus der beobachteten Drehung und der gewogenen Menge die specifische Drehung des Albumins berechnete, so ergab sich diese in den drei berücksichtigten Fällen zu $-42,9,-43,7$ und $-45,0^{\circ}$, im Mittel $\mathrm{zu}-43,9^{0}$, während $\mathrm{Stark \textrm {Ct } ^ { 1 }}$ ) die specifische Drehung des mucoidhaltigen Ovalbumins $\mathrm{zu}-37,79^{\circ}$ angibt.

Ich habe den Gegenstand weiter verfolgt und in zwölf anderen Fällen die aus der Gewichtsanalyse berechnete Drehung im Mittel $=-44,0^{\circ}$ gefunden. In fünf Fällen lag sie zwischen $-43,30$ und $-43,89^{\circ}$, in sechs Fällen zwischen - 44,01 und $-44,26^{\circ}$ und nur ein Mal über $-45^{\circ}$, nämlich bei $-45,10^{\circ}$. Die specifische Drehung schwankt demnach nur um ein Geringes um das Mittel von - 44,0 $0^{\circ}$, und darum durfte ohne wesentlichen Fehler für die Correctur der Gehalt des Ovalbumins an Mucoid als constant angenommen werden.

Nach der Bestimmung mittelst des Starke'schen Drehungscoëfficienten ergab sich, dass die zwölf Lösungen in $100 \mathrm{ccm}$ zusammen $61,345 \mathrm{~g}$ Ovalbumin enthalten hätten, während gewichtsanalytisch nur $52,686 \mathrm{~g}$ gefunden wurden. Demnach hätten 100 Ovalbumin 85,88 eigentliches Albumin nnd 14,12 Mucoid entbalten, oder auf 100 eigentliches Albumin wären 16,44 Mucoid gekommen. Dieses Ergebniss stimmt gut zu dem Resultate, zu welchem

1) K. V. Starke, Jahresbericht für Thierchemie Bd. 11 S. 19.1881. 
C. Th. Mörner $\mathbf{r}^{1}$ bei der Bestimmung des Mucoids im nativen Eiereiweiss auf gewichtsanalytischem Wege gelangt ist; nach ihm macht das Mucoid 12,53\% der organischen Substanz aus. Diese Zahl ist kleiner als die von mir gefundene, weil in der organischen Substanz des Albumens nicht bloss das Albumin, sondern auch andere organische Körper enthalten sind, von denen ihrer Mengen wegen hauptsächlich der Zucker und das Globulin in Betracht kommen. Nimmt man den Gehalt des wasserfreien Albumens an Zucker nach meiner Bestimmung ${ }^{2}$ ) zu 4,5\%, den an Globulin nach Dillner ${ }^{3}$ ) zu $6,6 \%$ an, so enthieite das Albumen in 100 Theilen an Albumin und Mucoid zusammen 88,9, wovon nach Mörner 12,53 Theile oder 14,1\% auf das Mucoid entfielen. Kann eine solche Rechnung auch keinen Anspruch auf grosse Genauigkeit machen, so stützt das Ergebniss doeh meine Angaben über den Gehalt des Ovalbumins an Mucoid.

Das zu den Versuchen dienende amorphe Oralbumin hat Schütz wesentlich nach dem Verfahren von Hammarsten dargestellt.

Mindestens 0,5 Liter Eiereiweifs wurde mit Salzsaure neutralisirt und durch Sattigen mit Magnesiumsulfat vollständig vom Globulin befreit, das Albumin dann nach $\mathrm{H}$ ofmeister $\mathrm{r}^{4}$ ) mit freie Schwefelsaure enthaltender gesattigter Magnesiumsulfatlösung niedergeschlagen und darauf in Pergamentschlauchen erst gegen fliessendes, dann gegen oft gewechseltes thymolisirtes destillirtes Wasser vollständig schwefelsäurefrei dialysirt. Die Dialyse allein nahm ungefahr 4 Wochen in Anspruch.

Die filtrirte Albuminlosung wurde weiter auf grossen flachen Tellern bei $40^{\circ}$ stark concentrirt, aber nicht vollständig eingetrocknet, die Flüssigkeit dann von den Tellern abgegossen. Bringt man das Albumin bei $40^{\circ}$ ganz zur Trockne, so wird ein grosser Theil des Albumins, mindestens ein Drittel, unlóslich. Die vereinigten Antheile wurden auf 1 Liter mit $1 \mathrm{ccm}$ einer Losung von $20 \mathrm{~g}$ Thymol in $100 \mathrm{ccm}$ Alkohol versetzt und konnten so längere Zeit unverändert aufbewahrt werden. Grosse Mengen Thymol fallen zwar mit der Zeit das Albumin, von der verwendeten kleineu Menge war aber in dieser Hinsicht kein Nachtheil wahrnehmbar.

Ich selbst habe spater auch das Globulin durch halbe Sättigung mit Ammonsulfat abgeschieden und das Albumin darauf nach Johansson ${ }^{5}$ )

1) C. Th. Mórner, a. a. O. S. 531.

2) Huppert, Zeitschrift für physiol. Chemie Bd. 9 S. 585. 1885.

3) H. Dilln er, Jahresber. f. Thierchemie Bd. 15 S. 31.1885.

4) F. Hofmeister, Zeitschr. f. analyt. Chemie Bd. 20 S. 319. 1881.

5) J. E. Johansson, Zeitschr. f. physiol. Chemie Bd. 9 S. 317. 1885. 
mit Essigsaure gefallt. Der Fäulniss während der Dialyse wurde mit Erfolg durch Eingiessen von Chloroform in die Pergamentschläuche vorgebeugt.

In Fällen, wo es mir auf eine absolute Entfernung des Globulins und auf eine vollige Abwesenheit von freier Säure oder säurebindenden Salzen nicht ankam, habe ich nach der von $\mathrm{Schutz^{1 }}$ ) mitgetheilten Vorschrift Ejereiweiss auf das Liter"mit $14 \mathrm{ccm}$ Salzsaure von 1,12 Dichte versetzt und filtrirt. Man verdünnt die Salzsäure vor dem Zusatz zum Eiweiss zweekmässig auf das doppelte Volumen. Von dem Filtrat enthalten $10 \mathrm{ccm}$ nahezu $1 \mathrm{~g}$ Eiweiss. Diese Lösung ist weiterhin im Gegensatz zur Albuminlösung als E iweisslosung bezeichnet. Die frische Lösung enthielt Zucker, und da die secundäre Albumose polarimetrisch bestimmt wird, so darf die Gegenwart des Zuckers nicht ausser Acht gelassen werden. Wie man dabei verfahren kann, ist am Schluss des ersten Abschnitts angegeben.

Da uns daran gelegen sein musste, möglichst reines, von Verdauungsproducten freies Pepsin zu verwenden, so haben wir uns dasselbe nach folgendem Verfahren dargestellt.

Die abgewaschene und abpräparirte Schleimhaut von 4-6 Schweinsmagen wurde mit 1,5-2 Liter Salzsäure von $0,3 \%$ unter Zusatz von überșchüssiger Salicylsäure bei $40^{\circ}$ digerirt. Wenn sich das Gewebe bis auf einen geringen Rest gelöst hatte, wurde das Filtrat gegen Thymolwasser so lange dialysirt, bis die äussere Flüssigkeit nach dem Eindampfen weder die Biuretprobe gab, noch mit Phosphorwolframsäure und Salzsäure getrubt wurde und der Inhalt der Schläuche keinen unverbrennlichen Rückstaud hinterliers. Es war dann auch alle Salzsäure entfernt. Die Flüssigkeit wurde dann nochmals mit Salicylsäure gesättigt, filtrirt und in hohen Cylindern aufbewahrt, wobei sich noch Mucin absetzte. Ob das Pepsin noch Albumose oder Albumose liefernde Substanz enthält, davon kann man sich in der Weise uberzeugen, dafs man einige Kubikcentimeter des Pepsins mit $100 \mathrm{ccm}$ Verdauungssalzsäure einen Tag bei Körpertemperatur stehen lässt und dann wie bei der unten beschriebenen quantitativen Bestimmung der secundären Albumose verfährt.

Die geringste Menge der zu diesen Versuchen verwendeten Pepsinlösung betrug $0,25 \mathrm{ccm}$. Um so kleine Volumina auch sicher abmessen zit können, wurde die ursprüngliche Lösung auf das Vier- bis Sechsfache verdünnt.

Als Verdauungssäure wurde eine Salzsäure von bekanntem Gehalt vorräthig gehalten, die mehr $\mathrm{HCl}$ enthielt, als die Verdauungsmischung enthalten sollte, z. B. $1 \mathrm{~g} \mathrm{HCl}$ in 3 oder in $10 \mathrm{ccm}$.

Zu den Verdaungsversuchen wurden die einzelnen Flüssigkeiten mit genauen Buretten in den beabsichtigten Mengen zusammengemessen und das Volumen in allen Fällen, in welchen

1) Schütz, Zeitschr. f. physiol. Chemie Bd. 9 S. 581 . 
hierüber nichts angegeben ist, durch destillirtes Wasser auf $100 \mathrm{ccm}$ ergänzt, und zwar erfolgte die Mischung in der Reihenfolge: Albumin, Wasser, Salzsäure, Pepsin. Das Albumin wurde mit dem Wasser verdünnt, um nicht die concentrirte Säure auf die concentrirte Albuminlösung einwirken zu lassen, und das Pepsin zuletzt zugesetzt, damit es sogleich mit einer sicher sauren Flüssigkeit in Berührung kam. Unser Pepsin verlor, wenn es vorübergehend auch nur yanz schwach alkalisch gemacht wurde, augenblicklich seine Wirksamkeit. Jeder einzelne Versuch wurde doppelt angestellt. Die einzelnen Proben wurden in ein grosses, bereits auf die gewünschte Temperatur erwärmtes Wasserbad (einen 10 Liter fassenden Topf) gebracht. Durch einen Soxhlet' schen Thermostaten liess sich die Temperatur bis auf $\pm 0,1^{\circ}$ constant halten. Medicinfläschchen, welche 150 bis $200 \mathrm{ccm}$ fassen, schwimmen mit $100 \mathrm{ccm}$ Inhalt aufrecht im Wasser, und deren lassen sich viele neben einander in dem Wasserbad unterbringen.

Zur Trennung und Bestimmung der einzelnen in der Versuchsflüssigkeit enthaltenen Eiweisskörper bediente sich Schütz des folgenden Verfahrens.

Nach Ablauf der für die Versuchsdauer bestimmten Zeit wurde der Inhalt aller Fläschchen in Bechergläser gespült, in welche vorher eine zur Neutralisation der Salzsäure ausreichende Menge Natronlauge gemessen war. Auf diese Weise wurde in allen Proben die Verdauung so gut als gleichzeitig unterbrochen. Die einzelnen Flüssigkeiten wurden dann auf schwach saure Reaction gebracht und so das Acidalbumin abgeschieden. Die Niederschläge wurden dann auf getrockneten und gewogenen aschefreien Filtern mit kaltem Thymolwasser gewaschen, bis eine Probe des Filtrats mit Phosphorwolframsäure und Salzsätrre keine Trübung mehr gab, und darauf noch, zur vollständigen Entfernung der Albumosen, mit heissem Wasser wieder bis zum Verschwinden derselben Eiweissreaction. Darnach wurden die Filter nach einander mit heissem Alkohol und mit Aether übergossen, bis das Filtrat auf einem Uhrglas keinen in gelinder Hitze flüchtigen Rückstand mehr hinterliess. Endlich wurden die Filter in Trockengläschen bei $120^{\circ}$ bis zur Gewichtsconstanz getrocknet und gewogen.

Wabrend das Auswaschen mit heissem Wasser in einigen Tagen beendet war, nahm das Auswaschen in der Kälte mehrere Wochen in Anspruch. Filtrat und Waschwasser wurden in dieser Zeit durch einen massigen Thymol- 
zusatz vor Fảulniss geschützt. Ich bin später bei ähnlichen Versuchen in viel kürzerer Zeit zum Ziele gelangt, wenn ich statt mit reinem Wasser mit einer 1-2\%igen Steinsalzlösung auswusch. Selbstverstandlich wurde das im Filter haftende Salz zuletzt auch weggewaschen.

Aus Filtrat und Waschwasser wurde darauf das Albumin bei passend saurer Reaction durch längeres Einstellen der Gläser in siedendes Wasser abgeschieden. Die Niederschläge wurden mit heissem Wasser eiweissfrei gewaschen und dann weiter wie die des Acidalbumins behandelt. Auch hier wurden die Filtrate und die Waschwässer thymolisirt.

Bei Weitem nicht jeder Niederschlag, welcher beim Kochen einer schwach sauren Verdauungsflüssigkeit auftritt, darf als Albumin angesehen werden. Eine Acidalbuminlösung, die nur so schwach sauer ist, dass das Acidalbumin gerade noch in Lösung bleibt, scheidet beim Kochen einen Eiweissniederschlag $a b$, wie bereits Meissner ${ }^{1}$ ) beobachtete, und nimmt dabei neutrale Reaction an. Entbält die Lösung noch coagulable Albumose (Heteroalbumose), so tritt sicher beim Erhitzen der auf saure Reaction gebrachten Flüssigkeit ein Niederschlag auf, der erheblich beträchtlicher ist als in der einfach neutralisirten Lösung, wenn man derselben vor dem $\mathrm{Ab}$ stumpfen der Säure noch 1-2\% Kochsalz hinzugesetzt und so das theilweise Ausfallen der Heteroalbumose beim Neutralisiren verhindert hat. Dieser Albumoseniederschlag ist aber wesentlich nur den Verdauungsproducten der Globuline eigenthümlich, wie dies bereits aus den Angaben der älteren Autoren hervorgeht.

Schwann ${ }^{2}$ ) verdaute Fibrin mit künstlichem Magensaft, schied das Acidalbumin durch Neutralisiren mit kohlensaurem Natron ab und erbielt dann beim Kochen des Filtrats einen starken Niederschlag. Gleiches beobachtete Me issner ${ }^{3}$ ) bei der Verdauung von Syntonin (und von Caseïn). Als er ferner aus der bei der Verdauung von Fibrin erhaltenen Lósung das Parapepton durch Neutralisiren und das Metapepton durch schwaches Ansäuern des Filtrats vollständig entfernt hatte, entstand in der ganz klaren Flüssigkeit bei neutraler oder sehr schwach saurer Reaction ein ansehnlicher Niederschlag, wenn man sie eine Weile auf $65-66^{\circ}$ (den Coagulationspunkt der Heteroalbumose) erhitzte. Das coagulable Product nahm darauf Brücke $e^{4}$ wahr bei der Verdalung von

1) G. Me issner, Zeitschr. f. ration. Med., 3. R., Bd. 8 S. 286.1860.

2) Schwann, Müller's Archiv 1836 S. 81 und 133.

3) Meissner, a. a. O. Bd. 10 S. 5 u. $11 \mathrm{ff}$., 1861; Bd. 12 S. 61. 1861.

4) Brúcke, Sitzungsber. d. k. Akad. d. Wissensch., math.-naturw. Classe Bd. 37 S. 180.1859.

E. P flüger, Arehiv für Physiologie. Ba. 80 . 
frischem Fibrin; es fehlte dagegen beim gekochten Fibrin, beim coagnlirten Eiereiweiss und beim Kalialbuminat; mit Kali behandeltes Fibrin lieferte das Product gleichfalls nicht oder nur in geringer Menge. An diese Beobachtungen schliessen sich dann die von $K \dot{u} h n$ e und Chittenden ${ }^{1}$ ) an.

Vor Allem kommt für uns das Verhalten des Albumins in Betracht. Im Gegensatz zu Brücke hat in dieser Hinsicht Wawrinsky²) bei der Verdauung von coagulirtem Eiereiweiss manchmal "beim Erhitzen gerinnendes Eiweiss" in kleinen Mengen angetroffen. Trotz mannigfacher Abänderung der Versuche ist es mir nicht gelungen, unter den Verdauungsproducten von löslichem Albumin, von Acidalbumin und von coagulirtem Albumin mit Sicherheit coagulable Albumose nachzuweisen. „Wie die Sättigung der neutralisirten Flüssigkeit mit Kochsalz ergab, enthielt sie zwar Albumose, aber beim Erwảrmen auf $64-66^{\circ}$, den Coagulationspunkt der Heteroalbumose, trúbte sie sich entweder gar nicht oder nur schwach.

Um mit Sicherheit darüber Auskunft zu erhalten, ob der bei der Verdauung von Albumin zuletzt noch in Lösung befindliche coagulable Eiweisskörper wirklich Albumin ist, habe ich einen Verdauungsversuch im Grossen angestellt und den löslichen Rest untersucht.

Das dazu dienende Eiereiweiss wurde nach S. 8 durch Zusatz ron Salzsaure von 1,12 Dichte vom Globulin befreit and dann so lange verdaut, bis nur ein unbedeutender Neutralisationsniederschlag entstand. Nach Entfernung desselben wurde die neutrale Flüssigkeit bei $40^{\circ}$ mit Magnesiumsulfat gesättigt, das Filtrat mit schwefelsaurehaltiger gesättigter Bittersalzlosung gefallt und der Niederschlag durch Dialyse bis auf Spuren von der Schwefelsaure befreit. Die Lösung enthielt dann noch in geringfügiger Menge einen durch Essigsäure fällbaren mucinartigen, wohl vom Pepsin herrührenden Eiweisskorper, der durch Zusatz von Essigsäure entfernt wurde. Bei passend saurer Reaction begann sich die Flüssigkeit bei $69,7^{\circ}$ zu trüben und schied zwischen 74,5 und $75^{\circ}$ Flocken aus. Die specifische Drehung des in Lösung befindlichen Eiweisskötpers wurde zu - 39,850 bestimmt, wahrend die des Eieralbumins nach Starke nur $-37,79^{\circ}$ beträgt. Dieser Befund steht keineswegs in Widerspruch mit der Annahme, dass die Flüssigkeit Albumin enthalten habe, denn der Drehungsunterschied erklärt sich jetzt schon allein daraus, dass sich neben dem Albumin in der Flussigkeit noch Ovomucoid befand, für dessen Entfernung nicht gesorgt war. Wie das Albumin

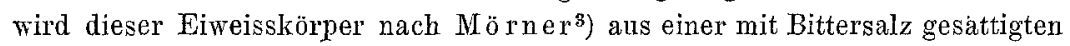
Losung durch freie Säure gefallt und hat so das Albumin in den Niederschlag begleitet. Das Ovalbumin besitzt die spec. Drehung $-37,79^{\circ}$; dem Oromucoid kommt aber, wie unten gezeigt wird, die spec. Drehung von $-65,48^{\circ} \mathrm{zu}$.

1) Kühne und Chittenden, Zeitschr. f. Biol. Bd. 20 S. 45.1884.

2) R. Wawrinsky, Jahresber. f. Thierchemie Bd. 3 S. 175.1873.

3) C. Th. Morner, a. a. O. S. 529. 
Aus diesen Drehungen berechnet sich der Gehalt des rückständigen Albumins an Mucoid zu 21,5\%, wảhrend dem ursprünglichen Eieralbumin ein solcher von nur 14,1\% zukommt. Diese Anreicherung erklärt sich einfach daraus, dass Albumin verdaut wurde und der auf dasselbe entfallende Antheil an Mucoid übrig geblieben ist.

Der durch Coagulation abgeschiedene Eiweisskörper muss nach dem Ausfall der Untersuchung als ein der Verdauung entgangener Rest Albumin angesehen werden.

Zur Ermittelung der specifis chen Drehung des Ovomucoids wurde es durch dreimalige Fällung seiner Lösung mit Alkohol, zuletzt unter Zusatz von Steinsalz, vom Zucker, durch Kochen seiner wassrigen Losung wieder vom Alkohol befreit. Um die Lösung vollig zu klären, wurde sie durch Asbest filtrirt.

Es kamen zwei Präparate verschiedener Darstellung zur Verwendung. Nachdem die Drehung derselben bestimmt worden war, wurden zwei mit einer genauen Burette abgemessene Volumina im Trockengläschen verdunstet und der Rückstand bei $120^{\circ}$ getrocknet. Zwei andere gleich grosse Volumina wurden in Platintiegeln zur Trockne gebracht, der Rückstand verkohlt, die Kohle sorgfältig mit heissem Wasser ausgewaschen, dann das Unlösliche verascht. Das Filtrat wurde eingedampft, der Rückstand mit Wasser vollständig in den Tiegel gebracht, das Wasser verdunstet und der Rückstand äber einer kleinen, den Tiegel nicht bis zur Rothgluth erhitzenden Flamme weiss gebrannt. So konnte einer Verflüchtigung von Chlornatrium mit Frfolg vorgebeugt werden.

Die eine Losung ergab $\alpha D=-2.9125^{\circ}$. Von derselben lieferten je $10 \mathrm{ccm}$

$$
\begin{aligned}
& 0,4601 \text { und } 0,4605 \mathrm{~g} \text { Trockenrückstand, } \\
& 0,0171 \text { und } 0,0179 \mathrm{~g} \text { Asche, somit } \\
& 0,4430 \text { und } 0,4426 \mathrm{~g} \text { Organisches. }
\end{aligned}
$$

In $100 \mathrm{ccm}$ waren also im Mittel 4,4280 g Organisches enthalten, woraus sich $[\alpha]_{D}=-65,77^{\circ}$ berechnet.

Von der zweiten Lösung, bei welcher $\alpha D=-2,210^{\circ}$ betrug, wurden je $12,5 \mathrm{ccm}$ analysirt. Es wurde gefunden

$$
\begin{aligned}
& 0,4469 \text { und } 0,4456 \mathrm{~g} \text { Trockenruckstand, } \\
& 0,0222 \text { und } 0,0227 \mathrm{~g} \text { Asche, somit } \\
& \hline 0,4247 \text { und } 0,4229 \mathrm{~g} \text { Organisches, }
\end{aligned}
$$

für $100 \mathrm{ccm}$ im Mittel also 3,3904. Daraus ergibt $\operatorname{sich}[\boldsymbol{\alpha}] \nu=-65,18^{\circ}$.

Das Mittel beider spec. Drehungen beträgt $-65,475^{\circ}$. K. A. H. Mörner ${ }^{1}$ ) hat $[\alpha]_{D}$ des Mucoids zu $-63,6^{\circ}$ bestimmt ${ }^{2}$ ).

1) K. A. H. Mörner, Skandinav. Archiv Bd. 6 S. 352.1895.

2) Auf Grund der Thatsache, dass das Ovalbumin im Mittel aus 85,88 Theilen echtem Albumin und 14,12 Theilen Mucoid besteht, berechnet sich mit Hùlfe der spec. Drehung des Mucoids $\left(-65,48^{\circ}\right)$ die spec. Drehung des reinen Eieralbumins $\mathrm{zu}-33,24^{\circ}$. 
Nach der Abscheidung des Albumins befinden sich nun noch in Lösung die Albumosen und das (echte) Pepton. Von diesen wurde die primäre Albumose in bekannter Weise durch Kochen mit Ferriacetat bei neutraler Reaction abgeschieden. Der Niederschlag wurde auf einem Glaswollfilter mit heissem Wasser eiweissfrei gewaschen und, um das Trocknen zu erleichtern, einige Male mit Alkohol übergossen. Bei $100^{\circ}$ schrumpfte der in feuchtem Zustand gelatinöse Rückstand zu einer spröden Masse zusammen. Da sich diese als sehr bygroskopisch erwies, konnte sie nur lufttrocken gewogen werden. Nachdem das Gewicht von Filter und Rückstand bestimmt war, wurde der Rückstand mit einem Glasstab möglichst vollständig und möglichst ohne Glasfäden losgelöst und das Filter zurückgewogen. Von dem aus dem Trichter entfernten Antheil des Niederschlags, dessen Gewicht also bekannt war, wurde der Stickstoffgehalt nach Dumas bestimmt und aus dem gefundenen Stickstoff die Menge der Albumose berechnet. Je ein Niederschlag reichte nur für eine einzige Stickstoff bestimmung aus.

Als diese Bestimmungen ausgefuhrt wurden, waren noch keine Angaben über den Stickstoffgehalt der Albumosen vorhanden, and er musste daher ermittelt werden. Die dazu erforderliche Albumose wurde durch Pepsinverdauung von Acidalbumin aus Eieralbumin dargestellt.

Das Weisse von 15 Eiern wurde durch Sattigen mit Magnesiumsulfat bei $40^{\circ}$ vom Globulin befreit, das Albumin aus dem Filtrat mit schwefelsäurehaltigem Magnesiumsulfat gefällt, der Niederschlag in Wasser gelöst und die Lösung neutralisirt. Das Filtrat wurde darauf bis zu $0,3 \%$ mit Salzsaure versetzt und 24 Stunden bei $40^{\circ}$ digerirt. Nach Ablauf dieser Zeit wurde das entstandene Acidalbumin durch Neutralisiren gefallt und abfiltrirt. Zur Reinigung wurde es einige Male in schwacher Salzsäure gelöst und durch Neutralisiren wieder abgeschieden und auf einem Filter zuerst mit kaltem, dann mit heissem Wasser gewaschen, bis das Filtrat mit Phosphorwolframsáure und Salzsaure nicht mehr getrubt wurde. Auf diese Weise wurden alle Eiweisskorper, auch das damals noch unbekannte Ovomucoid, aus dem Acidalbumin entfernt. Dasselbe wurde dann mit viel von unserem Pepsin der Verdaung untelworfen. Als das Acidalbumin nach 4 Stunden vollstảndig in Lósung gegangen war, wurde neutralisirt, aufgekocht und heiss filtrirt. In Filtrat liess sich Albumose nachweisen; es gab mit Essigsäure und Kochsalz einen Niederschlag, der sich beim Kochen löste und beim Erkalten wieder auftrat.

Um die primare Albumose von diffusiblen Verdaungsproducten zu befreien, wurde das Filtrat auf ein kleines Volumen eingedampft und so lange 
der Dialyse unterworfen, bis die Aussenflussigkeit mit Phosphorwolframsäure und Salzsäure keine Reaction mehr gab. Ob es auf diese Weise gelang, die primare Albumose zu isoliren, muss dahingestellt bleiben. Der Inhalt des Pergamentsclilauchs wurde eingedampft und bei $120^{\circ}$ getrocknet.

Von dieser Substanz habe ich den Stickstoffgehalt nach Dumas bestimmt. Es ergab sich dabei

$\begin{array}{ccccc}\text { Substanz g } & \text { ccm N } & \text { B. } & \text { T. } & \text { N\% } \\ 0,1977 & 28,0 & 746,1 & 20,0^{\circ} & 15,94 \\ 0,2669 & 37,0 & 746,1 & 19,7^{0} & 15,62 \\ 0,2512 & 35,3 & 742,0 & 20,0^{\circ} & 15,71 .\end{array}$

Die Substanz enthielt $0,207 \%$ Asche.

Im Mittel der drei Analysen beträgt der Stickstoffgehalt dieser Albumose 15,76\% und nach Abzug der 0,207\% Asche 15,79\%, genau so viel, wie $K \dot{u} h n e$ und Chittenden ${ }^{1}$ ) später für ihre unlösliche Hemialbumose aus Eiereiweiss angegeben haben. Diese Zahl wurde bei den Verdauungsversuchen von Schütz der Berechnung der primären Albumose zu Grunde gelegt.

Wie oben $\mathrm{S} .473$ gezeigt worden ist, wird mit der primären Albumose auch das aus dem amorphen Albumin stammende Mucoid gefällt. Der im Niederschlag gefundene Stickstoff konnte daher nicht ohne Weiteres in primäre Albumose umgerechnet werden, sondern erst nach Abzug des dem Mucoid angehörigen Stickstoffes, welcher nach Mörner ${ }^{2}$ ) 12,65\% beträgt. Wieviel aber Mucoid in den Eisenniederschlag gelangt ist, ergibt sich aus der Menge des verwendeten Albumins. Nach dem S. 475 mitgetheilten Befund bestehen 100 Theile des amorphen Albumins im Mittel aus 85,88 Theilen echtem Albumin und 14,12 Theilen Mucoid, oder auf 100 Theile echtes Albumin kommen 16,44 Theile Mucoid. Für 100 Theile gewichtsanalytisch bestimmtes Alburnin war also der 16,44 $\mathrm{g}$ Mucoid angehörige Stickstoff, nämlich $2,08 \mathrm{~g}$ von dem im Eisenniederschlag gefundenen Stickstoff abzuziehen und der Rest nach dem Stickstoffgehalt der primären Albumose $(15,79 \%)$ in diese Albumose umzurechnen.

In dem Filtrat von der primären Albumose war noch die secundäre Albumose zu bestinmen. Es geschah durch Polarisation. Die Flüssigkeit, aus welcher dje primäre Albumose gefällt

1) Kühne und Chittenden, Zeitschr. f. Biologie Bd. 19 S. 201.1883.

2) C. Th. Mörner, a. a. 0. S. 530. 
worden war, wurde mitsammt dem Niederschlag auf ein Volumen von $250 \mathrm{ccm}$ gebracht, vom Filtrat $200 \mathrm{ccm}$ auf ein Volumen von $40 \mathrm{ccm}$ eingedampft und so zur Polarisation verwendet. Die Lösung war jetzt fünf Mal so concentrirt als die ursprüngliche, wenn der Eisenniederschlag mit als Flüssigkeit gerechnet wurde. In feuchtem Zustand ist derselbe sehr voluminös, und der durch Vernachlässigung desselben bedingte Fehler erscheint darum sehr gross. Nach dem Trocknen überschritt das Gewicht desselben selten 0,25 g, hielt sich meist darunter, so dass der so begangene Fehler nicht weiter in Betracht kommt. Die Drehung der concentrirten Lösung wurde von Schütz im a-Decimeterrohr mittelst eines guten Wild'schen Polarimeters (von Dr. Hofmann in Paris) bestimmt.

Um die Menge der secundären Albumose in Gewichtsgrössen ausdrücken zu können, war die Kenntniss ihrer spec. Drehung erforderlich. Zur Ermittelung derselben wurde das Filtrat verwendet, welches nach der Abscheidung der primären Albumose mit Ferriacetat erhalten worden war.

Dasselbe wurde mit Salzsảure und Phosphorwolframsäure ausgefallt, der Niederschlag mit verdunnter Schwefelsaure chlorfrei gewaschen, dann mit Barythydrat zerlegt und der überschüssige Baryt mit Schwefelsäure genau ausgefällt. Die concentrirte Lösung ergab $\alpha_{D}=-2,273^{\circ}$. In je $13 \mathrm{ccm}$ wurde von mir gefunden

0,7240 und $0,7230 \mathrm{~g}$ bei $120^{\circ}$ trockner Rückstand, mit 0,0085 und $0,0085 \mathrm{~g}$ Asche,

demnach 0,7155 und $0,7145 \mathrm{~g}$ Organisches,

im Mittel also in $13 \mathrm{ccm} 0,7150 \mathrm{~g}$ oder in $100 \mathrm{ccm} 5,50 \mathrm{~g}$ organische Substanz.

Aus diesen Zahlen berechnet sich für die secundäre Albumose $[\alpha]_{D}=-41,33^{\circ}$. Da diese secundäre Albumose wahrscheinlich noch etwas sog. echtes Pepton enthalten hat und dieses durch die Phosphorwolframsäure thei]weise niedergeschlagen wird, so ist die spee. Drehung zwar mit einem kleinen Fehler behaftet, für unsren Zweck aber noch vollständig tauglich. Mittelst dieser spec. Drehung sind die Zahlen für die secundäre Albumose in den Tabellen von Schütz berechnet.

Diese Umrechnung der beobachteten Drehung in das Gewicht ist aber nur unter der Voraussetzung zulässig, dass die Verdaungsflussigkeiten mit Alkali (Natronlauge) neutralisirt wurden. P. MüIle $\mathbf{r}^{1}$ ) hat neuerdings ror-

1) P. Mủller, Zeitschr. f. plyysiol. Chemie Bd. 26 S. 51. 1898. 
geschlagen, die freie Sätre erst nahezu mit Lange zu neutralisiren und den Rest mit kohlensaurem Zink. Bei diesem Vexfahren erhalt man aber ganz andere Werthe, als wenn man bloss mit Alkali neutralisirt. Unter ganz gleichen Umständen habe icb nach dem Neutralisiren mit Lange eine Drehung von - $0,365^{\circ}$, nach dem Neutralisiren mit Zinkcarbonat eine Drehung von - $0,660^{\circ}$ beobachtet. Die mit dem Zinksalz behandelte Lósung enthielt Zink, und die enstandene Zinkalbumose besitzt somit eine hòhere spec. Drehung als die andere.

Für die Berechnung der Pepsineinheit hat sich $\mathrm{Schütz}$ ) einer anderen spec. Drehung bedient, nämlich der von $-65,3^{\circ}$. Die secundäre Albumose, aus welcher diese spec. Drehung abgeleitet wurde, war in anderer Weise dargestellt worden. Es wurde nämlich Eieralbumin bis auf einen kleinen Rest Acidalbumin verdaut, die Flüssigkeit mit Natronlauge fast ganz neutralisirt und das Filtrat nach und nach mit kleinen Mengen Alkohol versetzt, bis eine Probe der vom Niederschlag abfiltrirten Flussigkeit nach dem Verdunsten des Alkohols durch Ferrocyanwasserstoff nicht mehr getrübt wurde. In concentrirter Lösung besass diese Albumose eine spec. Drehung von $-57,76^{\circ}$, durch Verdunnen ging diese auf $-65,3^{\circ}$ hinauf. Das eingehaltene Verfahren bietet aber keine solche Sicherheit für die Entfernung des Mucoids, wie das Ausfällen mit Eisenacetat, und eine Beimengung ron Mucoid mit der spec. Drehung von $-65,48^{\circ}$ zu der secundären Albumose erklart die grosse Verschiedenheit der beiden spec. Drehungen.

Ein Fehler hätte in die polarimetrische Bestimmung der secundären Albumose dadurch eingeführt werden können, dass unsere Pepsinlösung mit Salicylsäure gesättigt war, und dadurch, dass Schütz die Albuminlösung durch einen Zusatz von Thymol conservirte. Beide Umstände sind aber obne Einfluss.

Nach Versuchen von $S \mathrm{chüt} z^{2}$ ) findet man, wenn in $100 \mathrm{ccm}$ Verdauungsflussigkeit an gesättigter Salicylsäurelösung enthalten war

für die secundare Albumose

$$
\begin{array}{llllllll}
0 & 2,5 & 4 & 6,2 & 8 & 25 & 49 & \mathrm{ccm},
\end{array}
$$

$$
2 \propto ⿻ 上=74,3 \quad 78,7 \quad 71,5 \quad 72,7 \quad 71,1 \quad 66,3 \quad 45,2 \text { Minuten }
$$

in negativen Werthen. Eine deutliche Verminderung der durch die Albumose bewirkten Drehung tritt also ein, wenn die Verdauungsmischung in $100 \mathrm{ccm}$ 2,5 ccm gesättigte Salicylsaurelösung, oder, da die Pepsinlosung mit Salicylsảure gesättigt war, ebensoviel Pepsinlösung enthält. In so grossen Mengen wurde aber das Pepsin von uns in keinem Fall angewendet.

Auch das Thymol erweist sich in der vorhandenen Nenge als unschádlich. Schüt $z^{3}$ ) hat ermittelt, dass sich die Ausbeute an secundarer Albumose erst dann vermindert, wenn die Verdaunngsmischung in $100 \mathrm{ccm}$

1) Schütz, Zeitschr. f'. physiol. Chemie Bd. 9 S. 589.

2) Schütz, Prager med. Wochenschr. 1885 Nr. 20 S. 195.

3) Schütz, Zeitschr. f. physiol. Chemie Bd. 9 S. 584. 
mehr als $0,01 \mathrm{~g}$ Thymol enthalt. Die ron Schütz benutzte Albuminlösung war aber auf das Liter mit $0,2 \mathrm{~g}$ Thymol in alkoholischer Lösung versetzt worden. Eine Störung hätte also nur dann eintreten können, wenn zur Herstellung einer $100 \mathrm{ccm}$ betragenden Verdauungsflüssigkeit mehr als $50 \mathrm{ccm}$ Albuminlösung verwendet worden wäre. Aber auch das war niemals der Fall.

In einer grossen Anzahl von Fällen habe ich in Gemeinschaft mit meinem damaligen Assistenten Fritz Kraus die secundäre Albumose allein bestimmt und mich dazu des von Schütz $z^{1}$ ) beschriebenen, oben $\mathrm{S}$. $13 \mathrm{ff}$. erwahnten Verfahrens bedient. Hier sind die beobachteten Drehungen nicht in Gewichte umgerechnet worden. Da es wünschenswerth war, ein Urtheil ủber die Genauigkeit der unter diesen Umständen erhaltenen Zahlen zu besitzen, habe ich die mittleren Abweichungen aller unter gleichen Bedingungen angestellten Versuchspaare berechnet, wobei sich folgendes Resultat ergab.

$\left.\begin{array}{ccc}\begin{array}{c}\text { Anzahl der } \\ \text { Versuchspaare }\end{array} & \begin{array}{c}\text { Drehung in } \\ \text { Minuten minus }\end{array} & \begin{array}{c}\text { Mittlere Abweichung } \\ \text { Minuten }\end{array} \\ 10 & \text { bis } 10 & 0,59 \\ 21 & " 20 & 1,27\end{array}\right\} 1,09$

Die Abweichungen wachsen also mit der Grosse der Drehung, oder, was dasselbe ist, mit der Concentration der Albumoselösung. Die Maxima der Abweichungen in den einzelnen Reihen waren im Mittel 2,5 mal so gross als die mittleren Abweichungen.

Der Zuckergehalt einer frischen Eiweisslösung ist so beträchtlich, dass man ihn bei der polarimetrischen Bestimmung der secundàren Albumose nicht rernachlassigen darf. Um den Fehler auszuscheiden, behandelt man gleichzeitig mit den Verdauungsversuchen ein abgemessenes Volumen der Eiweisslosung wie die Verdauungsflüssigkeit zur Bestimmung der secundären Albumose nnd zählt die beobachtete Rechtsdrehung den Linksdrehungen der secundären Albumose hinzu. Uebrigens verliert die Eiweisslösung mit oder ohne Zusatz von Hefe beim Stehen den Zucker.

\section{Die Ergebnisse der Verdaungsversuche.}

Die Versuche erstrecken sich ubber den Einfluss der Temperatur, der Säureconcëntration, der Albuminmenge, der Versuchsdauer und.

1) Scbütz, Daselbst Bd. 9 S. 587. 
der Pepsinmenge auf den Verlauf der Verdauung. Dementsprechend wurden immer nur die in Betracht kommenden Momente abgeändert und die übrigen Bedingungen gleish gebalten. Die von Schütz herrührenden grossen Tabellen geben im Kopf die Constanten an, in den Tahellen selbst neben den Resultaten die Variablen. Nebenher wurden von mir Versuche über den Einfluss des Volumens der Verdaunngsmischung auf das Resultat angestellt.

In vier Fällen (den ersten vier Tabellen) hat Schütz die Mengen des der Verdauung unterworfenen Albumins gewichtsanalytisch bestimmt, und diese sind in den Tabellen verwerthet. In den übrigen Fällen (den Pepsinversuchen, den ersten, welche Schütz anstellte) wurde die Albuminmenge polarimetrisch ermittelt; diese Werthe habe ich nach S. 483 in wahres Albumin umgerechnet. Das Mucoid, welches mit dem amorphen Ovalbumin in die Versuche eingeführt und mit der primären Albumose wieder entfernt wurde, ist aus der Rechnung ausgeschaltet.

Die primäre Albumose ist mit I. Albumose, die secundäre mit II. Albumose bezeichnet. Die „Summe der Producte“ enthält die Summe der drei Verdauungsproducte (Acidalbumin, primäre und secundäre Albumose). Das Verhältniss dieser Summe zu der Menge des verdauten Albumins, welches im letzten Stab angegeben ist, gestattet ein Urtheil über die ungefähre Genauigkeit der Resultate.

\section{Die Temperatur.}

In der Tabelle I(S.489) nehmen die Mengen der secundären Albu$\mathrm{m} 0$ s e im Allgemeinen regelmässig mit der Temperatur zu, nur $37,5^{\circ}$ macht eine Ausnahme, insofern als die hier bestimmte Zahl der bei $35^{0}$ beobachteten nahezu gleich ist. Dieser Werth kann aber nicht richtig sein, weil für die übrigen Temperaturen die Summe der Producte gleichmässig mit der Menge des verdauten Albumins wächst, für die Temperatur von $37,5^{\circ}$ aber nicht. Ich habe daher die Versuche wiederholt, aber nur die secundäre Albumose bestimmt.

Es wurde immer $1 \mathrm{~g}$ globulinfreies Eiereiweiss in $100 \mathrm{ccm}$ verdaut. In den zu derselben Reihe gehorigen Versuchen waren die Versuchsdauer und die Pepsinmenge dieselben, in den verschiedenen Reihen aber nicht immer. Der Säuregehalt betrug in der ersten und der letaten wagrechten Reihe $0,30 \%$, in den anderen 0,25\%. Es ergab sich dabei in Minuten für $2 \alpha D$ linksdrehend 


$\begin{array}{rcc}35^{\circ} & 37,5^{0} & 40^{\circ} \\ 36,20 & 47,54 & - \\ 43,27 & 45,22 & 50,09 \\ 44,42 & - & 53,24 \\ 47,36 & 50,99 & 57,03 \\ 61,45 & 77,88 & -\end{array}$

Nach dem Ausfall dieser Versuche erleidet die Bildung der secundären Albumose bei $37,5^{\circ}$, den anderen Temperaturen gegenüber keine Unterbrechung, sondern die Menge der secundären Albumose nimmt stetig mit der Temperatur zu.

Schütz hat die Beobachtungen noch über die Temperatur von $50^{\circ}$ ausgedehnt, dabei aber nur die secundäre Albumose bestimmt. Betrug diese bei $50^{\circ} 0,65 \mathrm{~g}$, so machte sie unter sonst gleichen Versuchsbedingungen bei $55^{\circ}$ nur $0,398 \mathrm{~g}$, bei $60^{\circ}$ noch weniger, nämlich nur $0,177 \mathrm{~g}$, aus. Das Temperaturoptimum für die Bildung der secundären Albumose liegt somit zwischen 50 und $55^{\circ}$, oder, da mit $50^{\circ}$ das Maximum schon überschritten sein kann, richtiger zwischen 40 und $55^{\circ}$.

Die Menge des verdauten Albumins wächst stetig mit der Temperatur, die des Acidalbumins gleichfalls, dieses aber nur bis $40^{\circ}$; bei $50^{\circ}$ vermindert sich seine Menge, offenbar nur desshalb, weil bei $50^{\circ}$ schon der ganze Albuminvorrath verbraucht ist. Die primäre Albumose zeigt keinen gail regelmässigen Verlauf, wohl hauptsächlich desshalb, weil die Bestimmung derselben mit grösseren Fehlern behaftet ist als die der anderen erwähnten Producte. Addirt man aber die Zahlen für Acidalbumin und primäre Albumose, so erhält mau

\begin{tabular}{lccccc} 
Temperatur & $30^{\circ}$ & $35^{\circ}$ & $37,5^{\circ}$ & $40^{\circ}$ & $50^{\circ}$ \\
Acidalbumin & 0,0563 & 0,0693 & 0,0705 & 0,0747 & 0,0613 \\
I. Albumose & 0,0958 & 0,0742 & 0,0739 & 0,0787 & 0,0755 \\
\cline { 2 - 6 } Summe & 0,1521 & 0,1435 & 0,1444 & 0,1534 & 0,1368
\end{tabular}

Die fünfte Summe kann nicht zum Vergleich herangezogen werden, weil das Acidalbumin wegen Mangels an Material $\mathrm{zu}$ klein ausgefallen ist; die vier anderen weichen aber von dem arithmetischen Mittel 0,1481 nur um Geringes ab. Es bleibt also die Summe der beiden Zwischenproducte zwischen Albumin und secundärer Albumose bei den verschiedenen Temperaturen nahezu gleich, während die Menge der secundären Albumose mit der Temperatur (bis ungefähr $50^{\circ}$ ) zunimmt. 
Ueber einige quantitative Verhältnisse bei der Pepsinverdaung. $\quad 489$

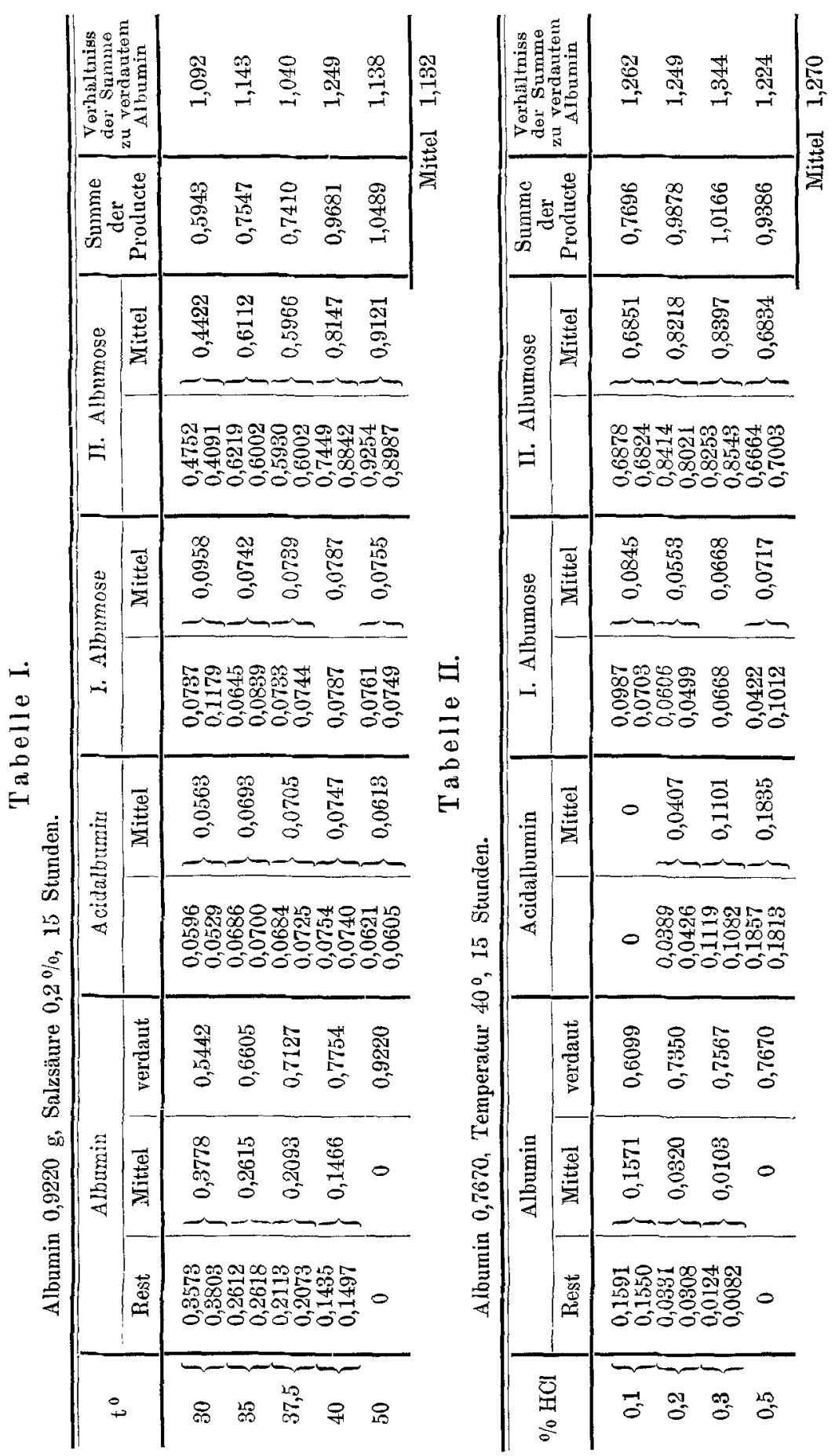


Berechnet man denjenigen Antheil, welcher von der Summe der beiden Albumosen auf die secundäre kommt, so ist zunächst die Menge derjenigen secundären Albumose zu corrigiren, welche bei $37,5^{\circ}$ bestimmt worden ist. Sie ist mit $0,5966 \mathrm{~g}$ zu klein bestimmt worden. Wenn man nun statt dieser Grösse 0,6966 als richtig annimmt, so wird der Quotient aus Summe der Producte und verdautem Albumin mit 1,180 den übrigen äbnlicher und das Mittel der Quotienten beträgt dann 1,160. Dann entfallen von der Summe der beiden Albumosen auf die secundäre bei den Temperaturen von $30-40^{\circ} 82,2,89,2,89,0$ und $91,2 \%$.

\section{Die Säureconcentration.}

Aus der Tabelle II von Schütz ergibt sich, dass die secundäre Albumose bei einer Steigerung der Säureconcentration von 0,1 auf $0,2 \%$ zunimmt, bei $0,3 \%$ auf der erreichten Höhe bleibt und sich mit $0,5 \%$ vermindert. Dieses Ergebniss stimmt im Allgemeinen mit älteren Erfahrungen überein, wenn diese auch nicht einen so bestimmten Ausdruck erhalten haben, wie ihn Schütz aus seinen Resultaten ableiten konnte. Für weitere bindende Schlüsse reicht die geringe Zahl der von $\mathrm{S}$ ch ütz beigebrachten Beobachtungen nicht aus.

Zunächst in der Absicht, für die von Scbütz für die secundäre Albumose gefundenen Werthe weitere Belege beizubringen, habe ich in Verdauungsversuchen dieses Product allein bestimmt. Zu den Versuchen habe ich amorphes Ovalhumin verwendet, weil dieses sicher ebensowenig freie Säure als säurebindende Salze enthält und so eine genaue Dosirung der Salzsäure zulässt.

Aus den Resultaten ergab sicb die gesetzmässige Weise näher, in welcher die Menge der secundären Albumose von der Concentration der Salzsäure abhängig ist. $B$ is $z u \quad 0,2 \% \mathrm{HCl}$ verhalten sich nämlich die Mengen der secundären Albumose wie die Quadratwurzeln aus den Säureconcentrationen. Für die höheren Säureconcentrationen sind die beobachteten Werthe um bestimmte Grössen kleiner, als die nach dem Wurzelverhältniss weiter berechneten und zwar verhalten sich diese Grössen zu einander wie die um 0,2 verminderten in Zehntelprocenten ausgedruckten Concentrationen. 
Als Belege für dieses Gesetz dienen folgende, unter verschiedenen Bedingungen gewonnene Versuchsergebnisse, in welchen die für die secundäre Albumose berechneten und gefundenen Werthe nach Linksdrehungen für $2 \alpha_{D}$ in Minuten unter einander gestellt sind. In allen Versuchen kam ungefähr $1 \mathrm{~g}$ Albumin in Verwendung, ausser in Versuch 1, wo die Menge grösser war.

\begin{tabular}{|c|c|c|c|c|}
\hline$\% \mathrm{HCl}$ & 0,10 & \multicolumn{2}{|c|}{0,15} & 0,20 \\
\hline gefunden & 90,38 & \multicolumn{2}{|c|}{116,09} & 125,52 \\
\hline berechnet & 91,23 & \multicolumn{2}{|c|}{111,74} & 129,02 \\
\hline$\% \mathrm{HCl}$ & 0,10 & 0,15 & 0,20 & 0,20 \\
\hline gefunden & $(13,26)$ & 32,52 & 36,57 & 54,42 \\
\hline berechnet & 26,65 & 32,64 & 37,58 & 53,10 \\
\hline
\end{tabular}

Der erste gefundene Werth ist aus der Berechnung weggelassen worden. In dem letzten Versuch mit $0,2 \% \mathrm{HCl}$ kam die doppelte Pepsinmenge in Anwendung.

In diesen Fällen, in welchen die Säureconcentration $0,2 \%$ nicht überschreitet, verhalten sich die Mengen der secundären Albumose wie die Wurzeln aus den Saureconcentrationen.

3. Ich habe auch vergleichsweise Albumin mit dem Minimum Säure und bei einer höheren Saureconcentration der Verdauung unterworfen. Als dieses Minimum habe ich diejenige Säuremenge betrachtet, welche im Stande ist, das aus einer gegebenen Albuminmenge im günstigsten Falle entstehende Acidalbumin noch in Lösung zu erhalten. Ungefähr $1 \mathrm{~g}$ Eiweiss wurde in $100 \mathrm{ccm}$ einer Salzsảure von $0,25 \%$ in der Warme stehen gelassen und darauf die Säure bis zu beginnender Trübung der Flüssigkeit neutralisirt. Der übrig bleibende Säurerest betrug 0,02\%. Nach vollstandiger Ausfällung des Acidalbumins waren nur noch ganz geringe Mengen Eiweiss in Lösung. Bei diesem Sauregrad $(0,02 \%)$ und bei dem von $0,25 \%$ wurden mit den zuerst verwendeten gleich grosse Proben Eiweiss verdaut und in diesen Fällen 15,6 und 45,1 Min. Linksdrehung beobachtet, während sich für die Sảureconcentrationen 14,6 und 46,1 berechnet.

\begin{tabular}{|c|c|c|c|c|c|c|}
\hline \multirow[t]{3}{*}{4.} & $\% \mathrm{HCl}$ & 0,1 & 0,2 & 0,3 & 0,4 & 0,5 \\
\hline & berechnet & 29,03 & 41,07 & 50,28 & 58,04 & 69,61 \\
\hline & gefunden & 29,00 & 41,10 & 40,97 & 38,18 & 33,86 \\
\hline \multirow{2}{*}{ Differenz } & f gefunden & 0,03 & $-0,03$ & 9,31 & 19,88 & 31,35 \\
\hline & I berechnet & & & 10,09 & 20,18 & 30,27 \\
\hline \multirow[t]{3}{*}{5.} & $\% \% \mathrm{HCl}$ & 0,10 & 0,20 & 0,23 & 0,26 & 0,30 \\
\hline & berechnet & 37,715 & 51,92 & 55,66 & 59,19 & 63,59 \\
\hline & gefunden & - & 51,92 & 51,12 & 51,42 & 51,48 \\
\hline \multirow{2}{*}{ Differenz } & gefunden & & & $\overline{4}, 54$ & 7,77 & 12,11 \\
\hline & I berechnet & & & 3,86 & 7,71 & 12.85 \\
\hline
\end{tabular}

In den beiden wagerechten Reihen der Fälle 4 und 5 sind die Drehungen nach der Wurzel aus der Saureconcentration berechnet auf Grund der 
Albumosemengen, welche bei Säureconcentrationen bis $0,2 \%$ beobachtet wurden. Von diesen berechneten Werthen sind die beobachteten abgezogen. Diese Differenzen verhalten sich aber, wie die letzte wagerechte Reihe zeigt, wie die Säureconcentrationen weniger 0.2 ; im Fall 4 also $1: 2: 3$, im Fall 5 wie $0,3: 0,6: 1,0$.

Nach diesem Ergebniss wird es bei einer gewissen Säureconcentration gar nicht mehr zu einer Bildung von secundärer Albumose kommen können. Für den unter 4. angeführten Fall würde diese Concentration $1,2 \%$ betragen.

Das quantitative Verhalten der übrigen in Frage kommenden Substanzen ergibt sich aus folgender Zusammenstellung:

$$
\begin{aligned}
& \% \mathrm{HCl} \\
& 0,1
\end{aligned}
$$

Verdautes Albumin

$\begin{array}{cccc}0,6099 & 0,7350 & 0,7567 & 0,7670 \\ 0 & 0,0407 & 0,1101 & 0,1835 \\ 0,0845 & 0,0553 & 0,0668 & 0,0717 \\ 0,0845 & 0,0960 & 0,1769 & 0,2552\end{array}$

Acidalbumin

I. Albumose

0,0845

0,0960

0,1769

Die Menge des verdauten Albumins nimmt mit der Concentration der Säure zu, vom Acidalbumin findet sich bei der Säureconcentration $0,1 \%$ nichts vor, bei der höheren Concentration bleiben von ihm aber mit der Concentration steigende Reste übrig; die Verdauung des Acidalbumins erfährt eine Verzögerung. An Stelle des Acidalbumins ist bei der Säureconcentration 0,1 eine erhebliche Menge primäre Albumose getreten; bei $0,2 \%$ nimmt diese stark ab und wächst bei den höheren Concentrationen wieder mässig an. Von der Summe der beiden Albumosen kommen auf die secundäre Albumose für die einzelnen Säureconcentrationen

$$
89,093,792,6 \text { und } 90,5 \% \text {. }
$$

In allen diesen Verhältnissen kommt die die Eiweisszerlegung befördernde Wirkung der Säure bis zur Concentration von $0,2 \%$ und die hemmende von Concentrationen über $0,2 \%$ zum Ausdruck.

\section{Die relativen Albuminmengen.}

(Siehe Tabelle III S. 493.)

Das Ergebniss dieser Versuchsreihe ist ein sehr einfaches. Die Mengen des verdauten Albumins, die Summen der Zwischenproducte und die Mengen der secundären Albumose steben in demselben Verbälniss wie die zu den Versuchen verwendeten Albuminmengen, nämlich wie $1: 2: 3: 4$. 
Ueber einige quantitative Verhältnisse bei der Pepsinverdauung. 493

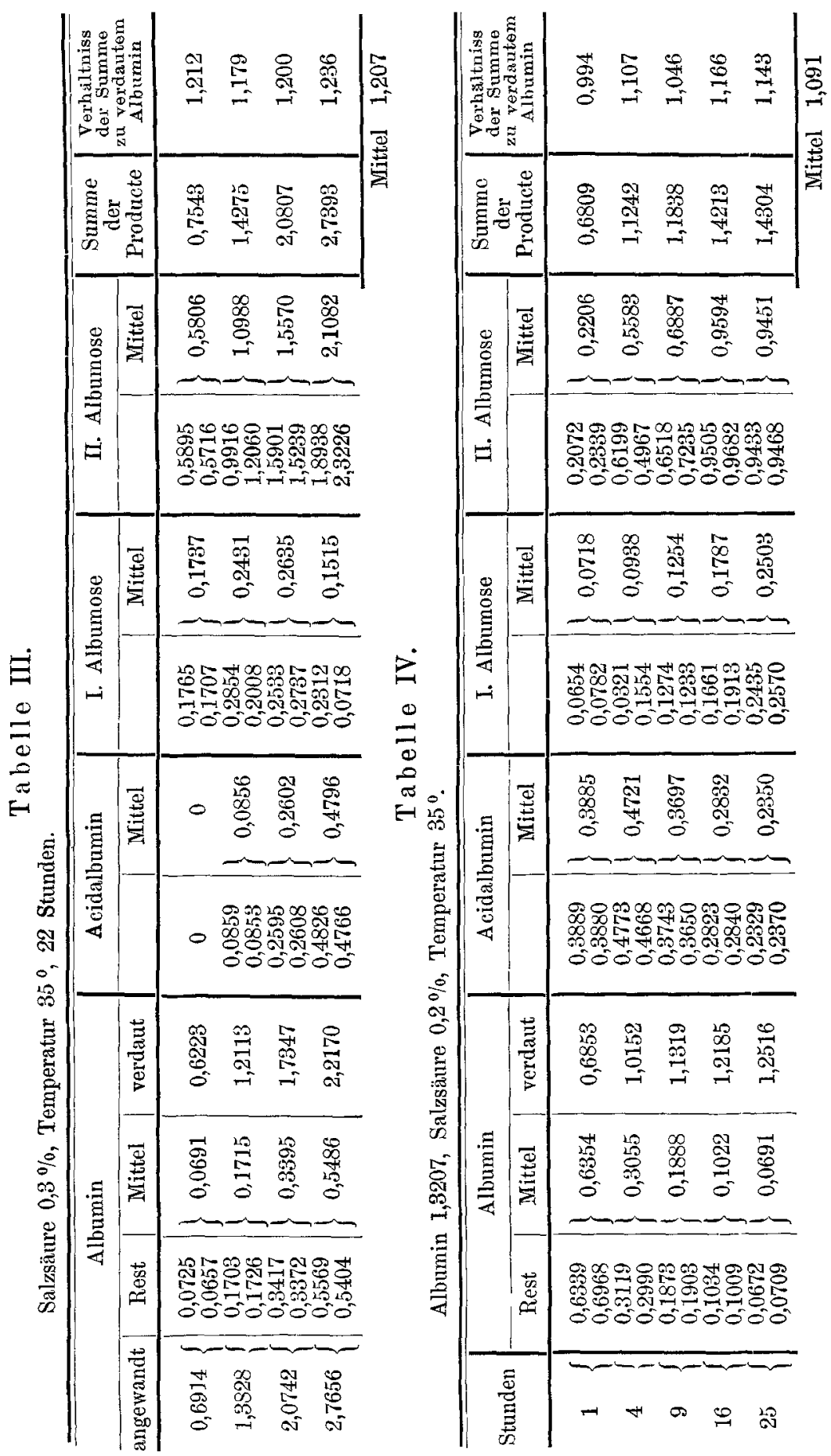


Das verdaute Albumin:

$\begin{array}{lllll}\text { gefunden } & 0,6223 & 1,2113 & 1,7347 & 2,2170 \\ \text { berechnet } & 0,5785 & 1,1571 & 1,7356 & 2,3141\end{array}$

Acidalbumin und primäre Albumose:

\begin{tabular}{|c|c|c|c|c|c|}
\hline \multirow{3}{*}{ gefunden } & Acidalbumin & 0 & 0,0856 & 0,2602 & 0,4796 \\
\hline & I. Albumose & 0,1737 & 0,2432 & 0,2635 & 0,1515 \\
\hline & Sum & 0,1737 & 0,3288 & 0,5237 & $(0,6311)$ \\
\hline & Summe & 0,1710 & 0,3420 & 0,5130 & 0,6840 \\
\hline
\end{tabular}

Die secundäre Albumose:

$\begin{array}{lllll}\text { gefunden } & 0,5806 & 1,0988 & 1,5570 & 2,1082 \\ \text { berechnet } & 0,5344 & 1,0689 & 1,6033 & 2,1378\end{array}$

Nur das aus der Rechnung weggelassene vierte Glied der Summe von Acidalbumin und primärer Albumose macht eine Ausnahme, die sich aber daraus erklärt, dass in den Einzelbestimmungen für die primäre Albumose von einander sehr abweichende Werthe, 0,2312 und 0,0718, gefunden wurden. Nach dem Versuchsprotokoll ist die kleinere, wegen unvollständiger Fällung, als unrichtig anzusehen. Im Uebrigen ist die Uebereinstimmung zwischen Befund und Rechnung eine so gute, als sie in Anbetracht der mannigfachen Fehlerquellen überhaupt sein kann.

Von der Summe der beiden Albumosen beträgt der auf die secundäre Albumose entfallende Antheil

$$
0,770 \quad 0,819 \quad 0,862 \quad 0,933,
$$

entsprechend dem Umstand, dass die secundäre Albumose mit der Vermehrung des Albumins schneller wächst als der Rest der primären Albumose.

\section{Die Versuchsdauer.}

(Siehe Tabelle IV S. 493.)

Vergleicht man zunächst wieder die Mengen der secundären Albumose miteinander, so ergibt sich, dass in 25 Stunden nicht mehr davon entsteht als in 16 Stunden, weiter aber, dass sich bis dahin die Mengen der secundären Albumose annähernd verhalten wie die Quadratwurzeln aus den Zeiten, wie folgende Zusammenstellung zeigt:

$\begin{array}{cccccc}\text { Stunden } & 1 & 4 & 9 & 16 & 25 \\ \text { gefunden } & 0,2206 & 0,5583 & 0,6887 & 0,9594 & 0,9451 \\ \text { berechnet } & 0,2427 & 0,4854 & 0,7283 & 0,9708 & \end{array}$


Im Anschluss an diese aus der Tabelle von Schütz wiederholten Zahlen führe ich die Beobachtungen an, bei welchen ich die secundäre Albumose allein bestimmt habe.

Es wurde in den sechs Gruppen immer nahezu 1 g Eiweiss verwendet, in den einzelnen Gliedern jeder Gruppe immer genau die gleiche Menge. In der Versuchsreihe 2 besass die Säure eine Concentration von $0,2 \%$, in den ubrigen Reihen eine solche von $0,25 \%$. Die Versuche unterscheiden sich ausser durch ihre Dauer noch durch die Temperatur, bei welcher sie angestellt wurden, und durch die Pepsinmenge. Die beobachtete Linksdrehung ist in Minuten angegeben.

1. Temperatur $30^{\circ}$.

$\begin{array}{lcccccc}\text { Stunden } & 1 & 4 & 9 & 16 & 25 & 36 \\ \text { gefunden } & 10,84 & 23,06 & 31,07 & 43,20 & 52,91 & 68,59 \\ \text { berechnet } & 10,7 & 21,4 & 32,1 & 42,8 & 53,5 & 64,2\end{array}$

2. Temperatur $35^{\circ}(0,2 \% \mathrm{HCl})$.

$\begin{array}{lllll}\text { gefunden } \quad 7,41 \quad 17,98 & 27,03 \quad 36,02\end{array}$

berechnet $\quad 9,003 \quad 18,01 \quad 27,01 \quad 36,01$

3. Temperatur $37,5^{\circ}$.

$\begin{array}{lllllll}\text { gefunden } & 10,63 & 23,05 & 31,80 & 43,78 & 54,07 & 66,09 \\ \text { berechnet } & 10,92 & 21,85 & 32,78 & 43,70 & 54,63 & 65,56\end{array}$

4. Temperatur $37,5^{\circ}$.

$\begin{array}{lllllll}\text { gefunden } & 20,31 & 34,57 & 53,50 & 64,63 & (65,73) & 74,20 \\ \text { berechnet } & 15,44 & 30,89 & 46,33 & 61,78 & 77,22 & 92,66\end{array}$

Von der Berechnung ist die eingeklammerte Zahl ausgeschlossen worden, weil sie offenbar unrichtig ist.

5. Temperatur $37,5^{\circ}$.

$\begin{array}{lcccccc}\text { Stunden } & 1 & 4 & 9 & 16 & 25 & 36 \\ \text { gefunden } & - & 28,37 & 40,84 & 48,55 & 56,79 & - \\ \text { berechnet } & - & 24,94 & 37,40 & 49,87 & 62,34 & -\end{array}$

6. Temperatur $40^{\circ}$.

$\begin{array}{lllllll}\text { gefunden } & - & 32,68 & 40,66 & 53,24 & 63,51 & 76,46 \\ \text { berechnet } & - & 26,66 & 39,98 & 53,31 & 66,64 & 79,97\end{array}$

Von den Reihen zeigen nur die drei ersten mit niederer Versuchstemperatur oder mässigen Pepsinmengen halbwegs befriedigende Uebereinstimmung der Rechnung mit dem Befund. Wo aber, wie in den anderen Reihen, der Process beschleunigt worden ist durch eine grössere Pepsinmenge oder durch eine höhere Temperatur, was die grössere Ausbeute an secundärer Albumose kenntlich macht, weicht das Resultat von der oben ausgesprochenen Regel in der Art $a b$, dass die gefund ene Menge der secundären Albumose in den ersten Zeiten des Versuchs grösser ist als die berechnete Menge, 
in den späteren Zeitabsehnitten dagegen kleiner. Nur mit dieser Einschränkung hat die aufgestellte Regel annähernd Gültigkeit. Dieses Verhältniss zeigt sich übrigens auch schon in der ersten, anscheinend einwurfsfreien Reihe. Die Regelmässigkeit, mit welcher diese Thatsache auftritt, schliesst den Zufall aus und lässt sie als den wahren Ausdruck für den Verlauf der Reaction erscheinen.

Aus den Versuchen von Schütz ergibt sich weiter, dass die Menge des verdauten Albumins mit der Dauer des Versuchs zunimmt; sie beträgt nach

$\begin{array}{cccccc}\text { Stunden } & 1 & 4 & 9 & \mathbf{1 6} & \mathbf{2 5} \\ & 0,6853 & 1,0153 & 1,1319 & 1,2185 & \mathbf{1 , 2 5 1 6}\end{array}$

Die Summevon Acidalbuminund primärer Albumose ist $\mathrm{zu}$ allen Zeiten eine constante. Es wurde bestimmt nach

\begin{tabular}{cccccc} 
Stunden & 1 & 4 & 9 & 16 & 25 \\
Acidalbumin & 0,3885 & 0,4721 & 0,3697 & 0,2832 & 0,2350 \\
I. Albumose & 0,0718 & 0,0938 & 0,1254 & 0,1787 & 0,2530 \\
\hline & 0,4603 & $(0,5659)$ & 0,4951 & 0,4619 & 0,4853
\end{tabular}

Nur die zweite Summe weicht mit 0,5659 von dem Mittel der übrigen, 0,4726, erheblich ab, die Menge des Acidalbumins ist um eine Einheit in der ersten Decimale zu gross. Sie ist als fehlerhaft zu bezeichnen.

Die Ergänzung der beiden Zwischenproducte zur Einheit erfolgt in der Weise, dass mit der Dauer des Versuches die Menge des Acidalbumins ab-, die der primären Albumose zunimmt. Die Mengen der primären Albumos e verhalten sich, mit Ausnahme der ersten Zahl, annähernd wie die Wurzeln aus den Versuchszeiten, wie aus nachstehendem Vergleich zu ersehen ist:

$\begin{array}{lccccc}\text { gefunden } & (0,0718) & 0,0938 & 0,1254 & 0,1787 & 0,2530 \\ \text { berechnet } & 0,0463 & 0,0926 & 0,1389 & 0,1852 & 0,2315\end{array}$

Von der Summe der beiden Albumosen kommen auf die secundäre Albumose bei der Versuchsdauer von

$\begin{array}{cccccc}\text { Stunden } & 1 & 4 & 9 & 16 & 25 \\ & 0,754 & 0,856 & 0,846 & 0,893 & 0,791\end{array}$

im Mittel aller Zahlen 0,818, im Mittel der drei mittleren 0,848 .

5. Die relativen Pepsinmengen.

Ueber den Einfluss der relativen Pepsinmenge auf den Gang der Verdauung hat Schütz die meisten Versuchsreihen angestellt. 
Sie waren die ersten der ganzen Untersuchung. In Bezug auf die Anordnung unterscheiden sich diese Versucbe von den anderen darin, dass Schütz den Gehalt der Albuminlösungen nicht gewichtsanalytisch, sondern polarimetrisch bestimmt hat. Aus den so gefundenen Mengen wurde dann die Menge des wahren Albumins nach S. 14 berechnet, was eine gewisse Unsicherheit in der Verwerthung einiger Ergebnisse zur Folge hatte. Ein weiterer schwerer in's Gewicht fallender Uebelstand ist der, dass wir in diesen ersten Untersuchungen die Trennung der beiden Albumosen insofern nicht so sorgfältig ausführten wie später, als wir die Prüfung der Flüssigkeit mit Ferrocyanwasserstoff unterliessen und uns begnügten, wenn die Flüssigkeit naç der Fällung völlig klar erschien. Desshalb sind die Bestimmungen der beiden Albumosen zum Theil unrichtig ausgefallen.

Die erste dieser Reihen sollte einen Anhalt dazu liefern, in welcher Art die Versuche am zweckmässigsten angeordnet würden. Da dieser erste Versuch sogleich ergab, dass sich die Mengen der secundären Albumose annähernd wie die Quadratwurzeln aus den Pepsinmengen verhielten, so wurden in den folgenden Versuchen die Pepsinmengen so gewählt, dass ihre Wurzeln ganze Zahlen darstellten. Um ferner den Einfluss der Nebenbedingungen auf den Verlauf der Reaction kennen zu lernen, hat $\mathrm{Schütz}$ bei diesen Versuchen die Säureconcentration, die Temperatur, die Versuchsdauer und die Albuminmenge versehieden gewäblt.

Nicht aus allen Versuchen ergab sich, dass sich die Mengen der secundären Albumose verhielten wie die Wurzeln aus den relativen Pepsinmengen; die Art des Ergebnisses erwies sich als abhängig von dem Verhältniss, in welchem die Pepsinmengen zu den Mengen des Albumins stehen. Diese Ausnahmen von der Regel, welche wir als Fälle mit abnormem Verlauf bezeichnen, gewährten aber gerade darum einen lehrreichen Einblick in das Wesen des Verdauungsprocesses.

Im Folgenden sollen zunächst zwei Pepsinversuche mit normalem Verlauf dargestellt werden. Abweichend von den übrigen Beobachtungen ist das Albumin in dem ersten Versuche bloss der Einwirkung der Salzsäure ausgesetzt gewesen.

(Siehe Tabelle V und VI S. 498.)

Das Verbältniss der gefundenen Menge der secundären Albumose zu den aus dem Wurzelverhältniss berechneten gestaltet sich in folgender Weise: 


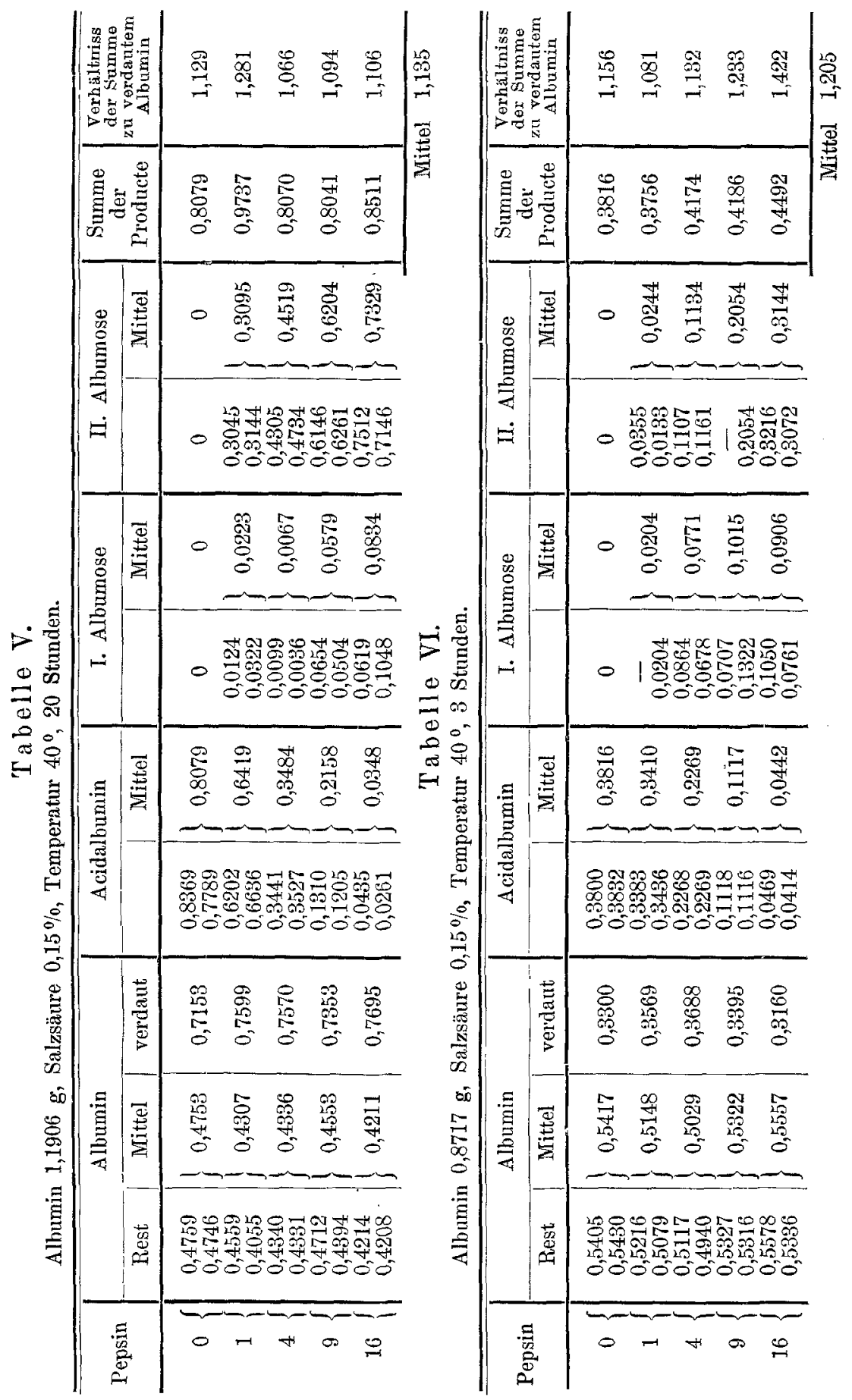


Ueber einige quantitative Verhältnisse bei der Pepsinverdauung.

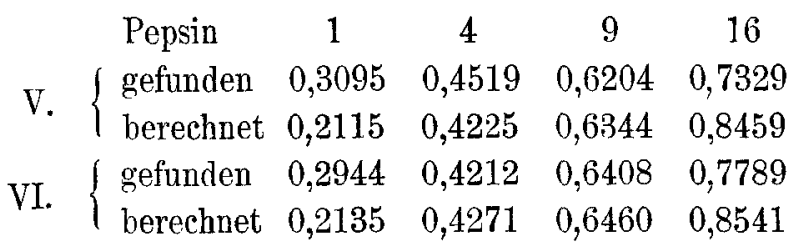

Wie bereits oben erwähnt wurde, sind diese Zahlen wegen der Unsicherheit in der Trennung der beiden Albumosen nicht ganz verlässlich. Schütz ${ }^{1}$ ) hat daher in anderen Versuchen nach einwurfsfreiem Verfahren die secundäre Albumose direct bestimmt. Nachstehend ist die für die secundäre Albumose beobachtete Ijinksdrehung, für $2 \alpha_{D}$, in Minuten angegeben.

\begin{tabular}{ccccccccc} 
1. Pepsin & 1 & 4 & 9 & 16 & 25 & 36 & 49 & 64 \\
gefunden & 9,40 & 20,61 & 32,33 & 45,35 & 55,21 & 64,96 & 75,97 & 85,25 \\
berechnet & 10,8 & 21,6 & 32,4 & 43,2 & 54,1 & 64,9 & 75,7 & 86,5 \\
2. Pepsin & 1 & & 2 & \multicolumn{2}{c}{3} & 4 & \\
gefunden & 53,96 & & 77,43 & 86,53 & 103,27 \\
berechnet & 52,10 & & 73,67 & 90,22 & 104,20 \\
3. Pepsin & 1 & 2 & 3 & 4 & 5 & 6 \\
gefunden & 7,30 & 9,75 & 12,80 & 14,80 & 16,50 & 18,45 \\
berechnet & 7,40 & 10,40 & 12,70 & 14,70 & 16,40 & 18,90
\end{tabular}

Schütz hat diese Versuche bei $37,5^{\circ}$ angestellt und 16 Stunden dauern lassen; der Salzsäuregehalt betrug $0,25 \%$. Dass das Resultat nicht an diese Bedingungen geknüpft ist, ergibt sich aus folgenden von mir ermittelten Zahlen:

In den Versuchen betrug die Eiweissmenge $1 \mathrm{~g}$, die Temperatur $40^{\circ}$, der Säuregehalt 0,25\% und die Versuchsdaner 20,12 und 3 Stunden.

\begin{tabular}{|c|c|c|c|c|c|}
\hline & Pepsin & 1 & 4 & 9 & 16 \\
\hline \multirow{2}{*}{$20 \mathrm{St}}$. & gefunden & $(10,73)$ & 25,43 & 41,06 & 54,32 \\
\hline & berechnet & 13,42 & 26,85 & 40,27 & 53,69 \\
\hline \multirow{2}{*}{$12 \mathrm{St}}$. & gefunden & 15,38 & 30,86 & 44,13 & $(50,45)$ \\
\hline & berechnet & 15,05 & 30,11 & 45,16 & 60,20 \\
\hline \multirow{2}{*}{3 St. } & gefunden & 7,86 & 15,99 & 24,14 & 30,21 \\
\hline & berechnet & 7,82 & 15,64 & 23,46 & 31,28 \\
\hline
\end{tabular}

Die eingeklammerten Zahlen sind von der Berechnung des Mittels ausgenommen.

Im 3- und im 12 stündigen Versuch kamen annähernd dieselben absoluten Pepsinmengen zur ${ }^{-}$Anwendung, und es stehen bei ihnen daher die Resultate

1) Schutz, Zeitschr. f. physiol. Chemie Bd. 9 S. 578. 
auch in dem Verhältniss zu den Wurzeln aus der Versuchsdauer. Der 12 stúndige Versuch ist von der Berechnung nach der Zeit ausgeschlossen, weil hier eine geringere Pepsinmenge angewendet wurde.

Weiter wurde ein Versuch mit $0,4 \%$ Salzsäure bei $37,5^{\circ}$ und mit 16 stündiger Versuchsdauer mit folgendem Resultat ausgeführt:

$\begin{array}{lcccc}\text { Pepsin } & 1 & 4 & 9 & 16 \\ \text { gefunden } & 10,86 & 25,80 & 35,86 & 49,59 \\ \text { berechnet } & 12,21 & 24,42 & 36,63 & 48,84\end{array}$

Aus den vorgelegten Zahlen folgt also, dass sich die Mengen der secundären Albumose verhalten wie die $Q$ uadratwurzeln aus den relativen Pepsinmengen.

Ein eigenthümliches Verbalten zeigt von den übrigen betheiligten Eiweisssubstanzen die Menge des verdauten Albumins. Diese bewegt sich bei Gegenwart von Pepsin in Tabelle V unregelmässig um das Mittel 0,7466, in Tabelle VI ebenso um das Mittel 0,3451.

Das Verbalten des Acidalbumins und der primären Albumose ist aus folgender Zusammenstellung ersichtlich:

\begin{tabular}{|c|c|c|c|c|c|}
\hline & 0 & 1 & $T$ & 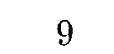 & 16 \\
\hline Acidalbumin & 8079 & 3419 & 484 & 258 & 0348 \\
\hline I. Albumose & 0 & 0,0223 & 0,0067 & 0,0579 & 0,0834 \\
\hline S & 08 & 0,6642 & 0,3551 & 0,1837 & 0,1182 \\
\hline & 3816 & & & & \\
\hline I. Albu & 0 & 0,0204 & 0,0771 & 0,1015 & 0,0906 \\
\hline & 8 &, 3614 & 0,3040 & 0,2132 & 0,1348 \\
\hline
\end{tabular}

In diesem Fall nimmt das Acidalbumin stetig ab, die primäre Albumose in der überwiegenden Mehrzahl der Beobachtungen zu, beide Substanzen ergänzen sich aber nicht zur Einheit, die Summe beider vermindert sich mit der Steigerung der Pepsinmenge.

Wegen der bereits hervorgehobenen Unsicherheit der Zahlen eignen sie sich wenig zu weitereı Schlüssen. Aber aus Tabelle V ergibt sich wenigstens, dass sich der erste und die zwei letzten Werthe der primären Albumose annähernd verhalten wie die Wurzeln aus den relativen Pepsinmengen, wie folgende Zusammenstellung zeigt:

$$
\begin{array}{llll}
\text { gefunden } & 0,0223 & 0,0579 & 0,0834 \\
\text { berechnet } & 0,0205 & 0,0614 & 0,0818
\end{array}
$$


und dass die Menge der secundären Albumose in diesen drei Beobachtungen einen nahezu constanten Bruchtheil von der Summe der beiden Albumosen ausmacht, nämlich 0,933, 0,915, 0,898, im Mittel 0,915 . Die Verhältnisse sind also solche, wie sie sich auch aus den Beobachtungen über die Versuchsdauer ergeben haben. Die bei der vierfachen Pepsinmenge bestimmte Menge der primären Albumose, 0,0067, fällt aus der Reihe, so dass sich hier die Albumosen nicht zur Berechnung eignen. Die betreffenden Zahlen der Tabelle VI gestatten dagegen eine solche Auslegung nicht.

Die Pepsinversuche mit abnormem Verlauf unterscheiden sich von den beschriebenen durch ein starkes Vorwalten des Pepsins und durch eine geringere Concentration der Salzsäure. Die Ergebnisse der zwei von Schütz angestellten Versuchsreihen sind in den folgenden Tabellen VII und VIII S. 502 enthalten.

Die Ergebnisse dieser Versuchsreihen weichen in mehrfacher Hinsicht von den in den beiden vorhergehenden Tabellen mitgetheilten ab. Es tritt in Gegenwart von Pepsin entweder gar kein Acidalbumin auf oder nur in Gegenwart der geringsten Pepsinmenge, und da auch nur sehr wenig. $\mathrm{Zu}$ einer Ansammlung von Acidalbumin, wie in den Versuchen der Tabellen V und VI kommt es nicht, es wird sofort nach seiner Entstehung aufgezehrt. Dieser Thatsache entspricht das Verhalten der secundären Albumose; ihre Menge nimmt zwar $\mathrm{zu}$, verhält sich aber keineswegs proportional der Wurzel aus den Pepsinmengen.

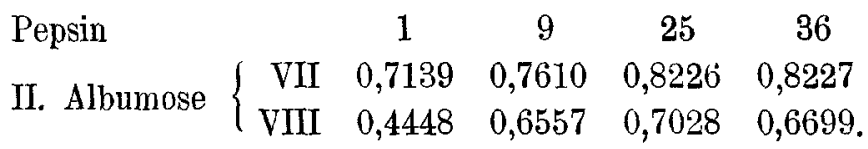

Das Wurzelverhältniss zwischen der Pepsinmenge und der Menge der secundären Albumose ist also an die Gegenwart von Acidalbumingeknupft, es tritt ein, solange ein Vorrath von Acidalbumin vorhanden ist, und bleibt aus, wenn das Acidalbumin fehlt.

Mit diesem Befund ist eine der Ursachen aufgedeckt, ans welchen die Bildung der secundaren Albumose nicht mehr in gesetzmässiger Abhängigkeit von der Pepsinmenge erfolgt. Je nach den Versuchsbedingungen wird die Regel früher oder spater ihre Gültigkeit verlieren. Für die Bestimmung der relativen Pepsinmenge hat $\mathrm{Schütz}$ als Bedingung die Verwendung von $1 \mathrm{~g}$ Albumin in $100 \mathrm{ccm} 0,2-0,3 \%$ Salzsäure und 16stundige Versuchsdauer bei $37,5^{\circ}$ gewählt, und eine Drehung der secundaren Albumose von 
E. Schutz und Huppert:

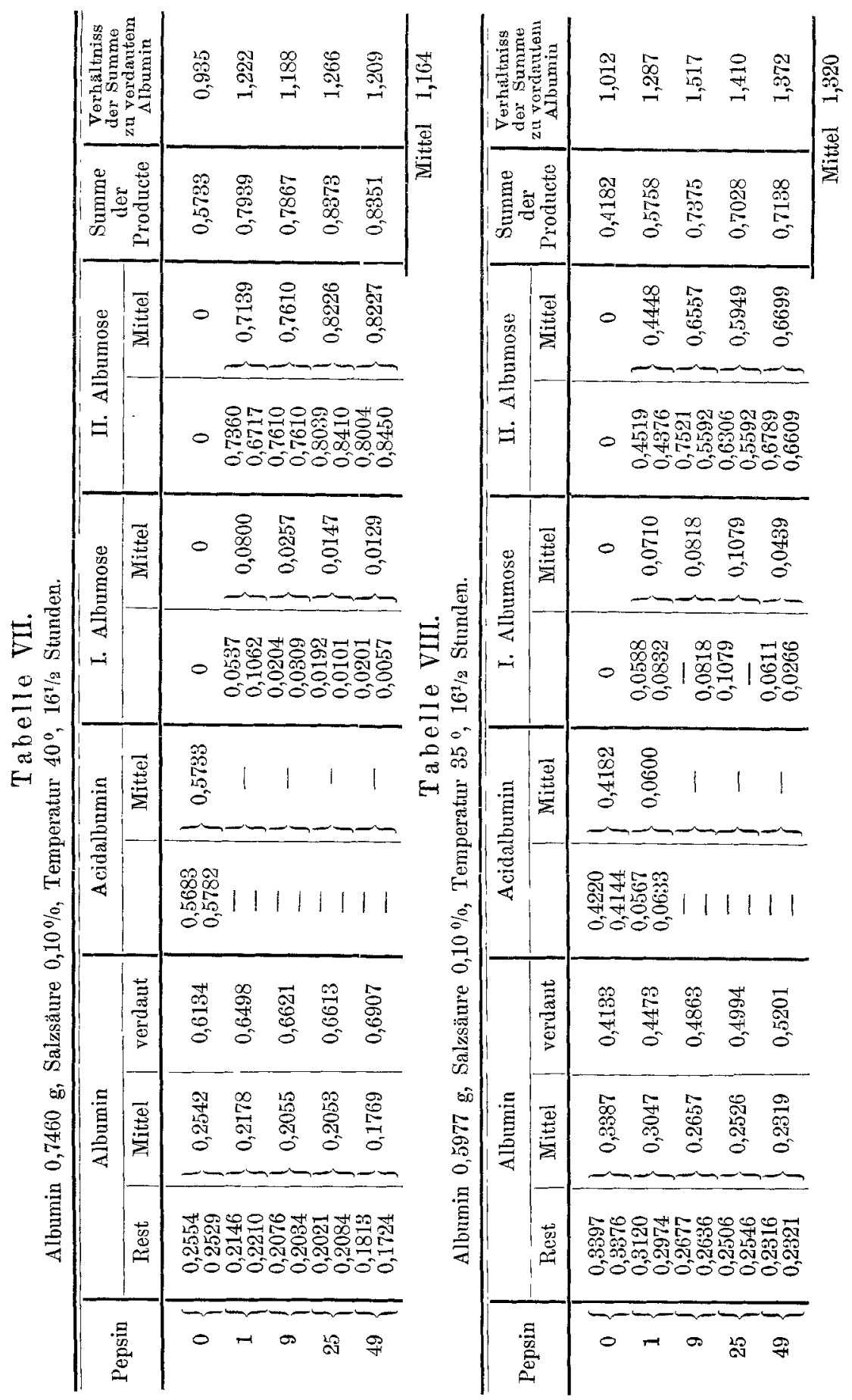


$2 a D=-100^{\prime}$ als obere Grenze angegeben. Auch ohne diesen Beleg ist es selbstverständlich, dass der gesetzmässige Ablauf einer an gewisse Substanzmengen gebundenen Reaction einmal ihr Ende erreicht, und die Verwunderung welche $\mathrm{Maly} \mathrm{y}^{1}$ ) über die von Schutz angegebene obere Grenze aussert, ist ohne alle Berechtigung.

Bei den früheren Pepsinversuchen ( $\mathrm{V}$ und VI) nahm die Menge der primären Albumose mit der Vermehrung des Pepsins zwar zu, die Summe von Acidalbumin und primärer Albumose aber ab. In dem vorliegenden Fall, wo mit Ausnahme des ersten Pepsinversuchs in Tabelle VIII als einziges Zwischenproduct primäre Albumose auftritt, sinkt ihre Menge mit der Vermehrung des Pepsins.

$\begin{array}{ccccc}\text { Pepsin } & 1 & 9 & 25 & 49 \\ \text { VII } & 0,0800 & 0,0257 & 0,0147 & 0,0129 \\ \text { VIII } & 0,1310 & 0,0818 & 0,1079 & 0,0439 .\end{array}$

Auch in diesen Reihen macht die secundäre Albumose einen nahezu constanten Bruchtheil von der Summe der beiden Albumosen aus; er beträgt bei

$\begin{array}{rlllll}\text { VII } & 0,899 & 0,967 & 0,987 & 0,985, \text { Mittel } & 0,960 \\ \text { VIII } & 0,862 & 0,889 & 0,847 & 0,939, \text { Mittel } & 0,884 .\end{array}$

6. Das Volumen.

Eine Untersuchung über den Einfluss, welchen das Volumen der Lösung auf die Ausbeute an secundärer Albumose ausübt, hatte für uns hauptsächlich nur ein methodologisches Interesse. Es fragte sich, ob es für das Resultat gleichgültig sei, wenn man bei gleichbleibender Concentration der Säure dieselben absoluten Mengen Albumin und Pepsin in verschieden grossen Volumen auf einander einwirken lässt, oder ob, wie wir es gethan haben, in Versuchen, deren Resultate verglichen werden sollen, immer das gleiche Volumen gewählt werden müsse.

Ich habe daher die secundäre Albumose in einigen Versuchen bestimmt, in welchen der Sauregehalt $0,25-0,30 \%$, die Temperatur $37,5^{\circ}$ und die Versuchsdauer, mit Ausnahme des 4. Versuchs, 16 Stunden betrug; im 4. Versuch wurde mit entsprechend mehr Pepsin nur 4 Stunden verdaut, so dass die Resultate dieses Versuchs mit denen der anderen direct vergleichbar sind. Die Albumose wurde für $2 \alpha D$ bestimmt, wobei sich als linksdrehend ergab in Minuten bei

1) Maly, Jahresber. f. Thierchemie Bd. 15 S. 267. 


$$
\begin{array}{cccccc}
25 & 50 & 100 & 150 & 200 & 250 \mathrm{~cm} \\
- & 55,5 & 60,5 & - & - & - \\
- & 47,2 & 56,4 & 50,0 & - & - \\
- & 51,9 & 51,0 & 56,9 & - & - \\
- & - & 92,8 & - & 104,7 & - \\
37,7 & - & 49,3 & - & - & 56,9
\end{array}
$$

Setzt man die bei $100 \mathrm{ccm}$ gefundenen Drehungswerthe $=50$ und reducirt darauf die übrigen Zahlen, so ergibt sich im Mittel

$38,2 \quad 46,2 \quad 50,0 \quad 50,1 \quad 56,4 \quad 57,7$

Nach diesen Ergebnissen wird, wie vorauszusehen war, die Menge der secundären Albumose von dem Volumen der Verdauungslösung im Allgemeinen in dem Sinne beeinflusst, dass um so mehr secundäre Albumose entsteht, je grösser das Volumen ist. In der Lösung blieben die absoluten Mengen des Albumins und des Pepsins constant, die Salzsäure aber war, bei gleichbleibendem Procentgehalt, in dem grösseren Volumen auch in grösserer absoluter Menge enthalten. Bei gleichbleibender relativer Menge beschleunigt also eine absolut grössere Menge Salzsäure die Verdaung.

\section{Der genetische Zusammenhang der Erscheinnngen.}

Welchen Antheil jedes der beiden bei der Verdauung thätigen Reagentien, Salzsäure und Pepsin, auf den Gang des Processes besitzt, lässt sich aus den vorliegenden Untersuchungen ableiten. Einen verlässlichen Anhalt zur Beurtheilung dieses Verhältnisses liefern die zwei Pepsinversuche mit abnormem Verlauf (VII und VIII). In diesen fehlt das Acidalbumin gleich vom Anfang oder von der zweiten Versuchsreilhe an, und dementsprechend schreitet die Bildung der secundären Albumose entweder gar nicht fort oder in geringfügiger Weise; diese schwache Zunahme der secundären Albumose erklärt sich aber aus einer entsprechenden Abnahme der primären Albumose. Folgende Zahlen liefern hierfür den Beleg.

$\begin{array}{lllll}\text { Pepsin } & 1 & 9 & 25 & 49\end{array}$

$$
\begin{aligned}
& \text { VII }\left\{\begin{array}{rrrrr}
\text { II. Albumose } & 0,7139 & 0,7610 & 0,8226 & 0,8229 \\
\text { I. Albumose } & 0,0800 & 0,0257 & 0,0147 & 0,0129
\end{array}\right. \\
& \text { VIII }\left\{\begin{array}{ccccc}
\text { II. Albumose } & - & 0,6557 & 0,5949 & 0,6699 \\
\text { I. Albumose } & - & 0,0818 & 0,1079 & 0,0439 .
\end{array}\right.
\end{aligned}
$$

Die Bildung der secundären Albumose ist also abhängig von der Gegenwart des Acidalbumins. Wo dieses fehlt, entsteht auch 
keine secundäre Albumose. Hiermit bestätigt sich die von Meissner ${ }^{1}$ ) ausgesprochene Vermuthung, dass nicht das Albumin direct, sondern erst nach seiner Umwandlung in Acidalbumin verdaut, vom Pepsin angegriffen wird. Die Pepsinverdauung zerfällt daher in zwei gesonderte Abschnitte, in die Verwandlung des Albumins in Acidalbumin durch die Säure und in die Ueberführung des Acidalbumins in Albumosen durch das Pepsin.

Da das Acidalbumin die nothwendige Vorstufe der Albumose bildet und dieses aus dem Albumin hervorgeht, so ist man berechtigt, die Menge des verdauten Albumins der des Acidalbumins, wenn nicht gleich, so doch proportional zu setzen. (In den vier blinden Versuchen von Schütz [V-VIII] kommen im Mittel auf 100 verdautes Albumin 106 Acidalbumin.) Von dieser Thatsache wird man Gebrauch machen müssen in den Fällen, in welchen sich wegen gleichzeitiger Gegenwart von Pepsin die Menge des überhaupt entstandenen Acidalbumins in keiner andern Weise ermitteln lässt; denn die in den Versuchen bestimmten Acidalbuminmengen sind nur die Reste, welche der Einwirkung des Pepsins entgangen sind. Die Frage, von welchen Bedingungen die Menge des gebildeten Acidalbumins abhängt, ist aber nach dem oben aufgestellten Satze die nächstliegende. Bei den Pepsinversuchen ergibt sich nun an verdautem Albumin bei

$\begin{array}{ccccc}\text { Pepsin } & 1 & 4 & 9 & 16 \\ \text { V } & 0,7599 & 0,7570 & 0,7353 & 0,7695 \\ \text { VI } & 0,3569 & 0,3688 & 0,3395 & 0,3160 \\ \text { Pepsin } & 1 & 9 & 25 & 49 \\ \text { VII } & 0,6498 & 0,6621 & 0,6613 & 0,6907 \\ \text { VIII } & 0,4473 & 0,4863 & 0,4994 & 0,5201\end{array}$

In der ersten Reihe bewegen sich die Zahlen unregelmässig um das Mittel 0,7554, in der zweiten Reihe scheint eine Abnahme, in den beiden letzten Reihen eine Zunahme des verdauten Albumins stattzufinden. Von diesen beiden Reihen hat die VIII. minder verlässliche Werthe ergeben, da hier das Verhältniss der Summe der Verdauungsproducte zu der Menge des verdauten Albumins im Mittel 1,320 (bis 1,517 ) beträgt und somit die in anderen Versuchen beobachtete Verhältnisszahl stark überschreitet. Addirt man die ent-

1) Meissner, a. a. O. Bd. 8 S. 292. 
sprechenden Werthe der drei übrigen Reihen (V-VII), so erhält man als Summen 1,7666, 1,7899, 1,7361 und 1,7762 mit dem Mittel 1,7667. Darnach ist die Menge des verdauten Albumins in den einzelnen Versuchsreihen als constant anzusehen. Es würde daraus weiter folgen, dass eine bis zum 25- und 49 fachen gesteigerte Pepsinmenge keinen Einfluss auf die Bildung des Acidalbumins ausübt; diese wird allein durch die Salzsäure bewirkt, die Menge des gebildeten Acidalbumins blieb aber in den einzelnen Reihen darum constant, weil die Bedingungen für die Acidalbuminbildung unverändert blieben, nämlich die Concentration der Säure, die Albuminmenge, die Temperatur und die Dauer der Einwirkung.

Die anderen Verdaungsversuche weichen in dieser Hinsicht insofern von den Pepsinversuchen $a b$, als die Bedingungen für die Bildung des Acidalbumins derart geändert waren, dass eine Zunahme des Acidalbumins stattfand. Die Mengen des verdauten Albumins, welche in den einzelnen Versuchen ermittelt wurden, sind folgende:

1. Temperatur

\begin{tabular}{|c|c|c|c|}
\hline $\begin{array}{l}30^{\circ} \\
5449\end{array}$ & $35^{\circ}$ & $\begin{array}{r}37,5^{\circ} \\
07197\end{array}$ & $\begin{array}{r}40^{\circ} \\
0.7754\end{array}$ \\
\hline
\end{tabular}

Die Richtigkeit der Zahl für $50^{\circ}$ steht in Zweifel, weil bei dieser Temperatur das Albumin ganz verbraucht war.

2. Albuminmenge

$\begin{array}{ccccc}\text { Albumin } & 1 & 2 & 3 & 4 \\ & 0,6223 & 1,2113 & 1,7347 & 2,2170 .\end{array}$

Die Zahlen stehen nahezu in demselben Verhältniss wie die ursprünglichen Albuminmengen.

3. Dauer des Versuchs

$\begin{array}{cccccc}\text { Stunden } & 1 & 4 & 9 & 16 & 25 \\ & 0,6853 & 1,0152 & 1,1319 & 1,2185 & 1,2516\end{array}$

4. Säureconcentration

$\begin{array}{ccccc}\% \mathrm{HCl} & 0,1 & 0,2 & 0,3 & 0,5 \\ & 0,6099 & 0,7350 & 0,7567 & 0,7670 .\end{array}$

Auch in diesem Fall war bei der höcbsten Säureconcentration zuletzt kein Albumin mehr vorhanden, und ist die letzte Zahl daher nicht verlässlich.

Die Differenz zwischen diesen Zahlen, den Mengen des gebildeten Acidalbumins und den zugehörigen Acidalbuminresten, ergibt 
Ueber einige quantitative Verhaltnisse bei der Pepsinverdaung. $\quad 507$

die Menge des verdauten Acidalbumins. Die absoluten Werthe derselben nehmen in folgenden Fällen mit der Steigerung: der Versuchsbedingungen zu.

1. Temperatur

\begin{tabular}{|c|c|c|c|}
\hline $30^{\circ}$ & $35^{0}$ & $37,5^{\circ}$ & $40^{\circ}$ \\
\hline 0,4879 & 0,5912 & 0,6422 & 0,7007 \\
\hline
\end{tabular}

2. Albuminmenge

$\begin{array}{ccccc}\text { Albumin } & 1 & 2 & 3 & 4 \\ & 0,6223 & 1,1257 & 1,4745 & 1,7374 .\end{array}$

Diese Zahlen verhalten sich nicht wie die Albuminmengen.

3. Versuchsdauer

$\begin{array}{cccccc}\text { Stunden } & 1 & 4 & 9 & 16 & 25 \\ & 0,2968 & 0,5431 & 0,7622 & 0,9353 & 1,0166 .\end{array}$

Berechnet man diese Zahlen nach dem Wurzelverhältniss, so ergibt sich :

$$
0,2369 \quad 0,4739 \quad 0,7108 \quad 0,9477 \quad 1,1847 .
$$

Die Rechnung verhält sich zu dem Befund in demselben Sinne wie bei der Bildung der secundären Albumose; anfangs verläuft die Verdauung des Acidalbumins schneller, zuletzt langsamer als nach der Wurzel aus den Zeiten.

4. Pepsin

$\begin{array}{ccccc} & 1 & 4 & 9 & 16 \\ \text { V } & 0,1180 & 0,4086 & 0,6095 & 0,7347 \\ \text { VI } & 0,0159 & 0,1419 & 0,2278 & 0,2718 .\end{array}$

In der Reihe $\mathrm{V}$ verhalten sich die Mengen des verdauten Acidalbumins annähernd wie die Wurzeln aus den Pepsinmengen; die Rechnung ergibt:

$$
0,1871 \quad 0,3742 \quad 0,5612 \quad 0,7483 .
$$

Für Reihe VI berechnet sich in derselben Weise, wenn man die erste Zahl unberücksichtigt lässt,

$$
(0,0713) \quad 0,1426 \quad 0,2138 \quad 0,2858 .
$$

5. Anders gestalten sich die Verhältnisse bei der Säureconcentration; hier wurde an Acidalbumin verdaut bei

$$
\begin{array}{ccccc}
\% \mathrm{HCl} & 0,1 & 0,2 & 0,3 & 0,5 \\
& 0,6090 & 0,6943 & 0,6406 & 0,5845 .
\end{array}
$$

Fine Steigerung findet nur statt bei der Zunahme der Säureconcentration von 0,1 auf $0,2 \%$, aber bis $0,5 \%$ sinkt die Menge 
des verdauten Acidalbumins wieder. Die Verdauung des Acidalbumins folgt also derselben Regel wie die Bildung der secundären Albumose.

Vergleicht man in den einzelnen Versuchen die Mengen des gebildeten Acidalbumins mit den Mengen des verdauten Acidalbumins, so stellen sich grosse Unterschiede heraus, wie folgende Zusammenstellung zeigt, in welcher die Menge des verdauten Acidalbumins in Procenten des gebildeten ausgedräckt ist.

\begin{tabular}{ccccc} 
Pepsin & \multicolumn{1}{c}{1} & 4 & 9 & 16 \\
V & 15,5 & 56,3 & 79,2 & $95,5 \%$ \\
VI & 4,5 & 37,9 & 67,1 & $86,0 \%$.
\end{tabular}

Aus diesen Zahlen geht hervor, dass der Abbau des Acidalbumins mit grösserer Geschwindigkeit erfolgt als die Bildung des Acidalbumins. Für den Pepsinversuch ist dieses Verbältniss einleuchtend, denn die Acidalbuminmenge war in den einzelnen Reihen constant, während der Verbrauch an Acidalbumin durch das Pepsin mit der Menge desselben zunahm.

Ein ähnliches Verhältniss ergibt sich bei den Versuchen über die Versuchsdauer. Es betrug die Menge des verdauten Acidalbumins in Procenten des gebildeten nach

$\begin{array}{cccccc}\text { Stunden } & 1 & 4 & \mathbf{9} & \mathbf{1 6} & \mathbf{2 5} \\ & 43,3 & 53,5 & 67,3 & \mathbf{7 6 , 8} & 81,2 \% \text {. }\end{array}$

Das gebildete Acidalbumin zeigt von der vierten, noch mehr von der neunten Stunde an eine so geringe Zunahme, dass diese von der Bildung der weiteren Verdauungsproducte beträchtlich überholt wird. Das angeführte relative Verbältniss steht im Einklang mit der Thatsache, dass die Bildung der secundären Albumose annähernd proportional der Wurzel aus der Zeit erfolgt, also in diesem Falle annähernd wie $1: 2: 3: 4: 5$. Die Producte der Acidalbuminverdauung bestehen aber nicht bloss aus der secundären Albumose, sondern es kommt zu dieser noch die primäre hinzu, und diese Summe liegt dem relativen Verhältniss zu Grunde.

Bei den Temperaturversuchen berechnet sich für die Mengen des verbrauchten Albumins auf 100 des gebildeten

$$
\begin{array}{ccccc}
\text { bei } & 30 & 35 & 37,5 & 40^{\circ} \\
& 89,6 & 89,5 & 90,1 & 90,4,
\end{array}
$$

im Mittel 89,9. Es wird also durch die Erhöhung der Temperatur die Bildung und der Verbrauch des Acidalbumins in gleichem Grade beschleunigt. Für die Temperatur von $50^{\circ}$ ergibt sich als Verbält- 
nisszahl 93,5; sie weicht aus dem Grunde etwas stärker vom Mittel ab als die übrigen, weil hier der Acidalbuminrest, abweichend von dem Verhalten der anderen Reihen, abgenommen statt zugenommen hat. Die Verlässlichkeit dieser Zahl kann demnach als zweifelhaft erscheinen.

In den Versuchen mit verschiedenen Album jnmengen nimmt das Verhältniss zwischen dem verdauten Albumin und dem gebildeten ab. Von 100 gebildetem Acidalbumin entfallen auf verdautes Acidalbumin bei

$\begin{array}{ccccc}\text { Albumin } & 1 & 2 & 3 & 4 \\ & 100 & 92,9 & 85,1 & 78,4 .\end{array}$

Die Menge des gebildeten Acidalbumins wuchs proportional der Menge des Albumins, die in den vier Versuchsreihen gleich gehaltene Menge Pepsin hat aber nicht ausgereicht, das Acidalbumin in dem Maasse seiner Entstehung weiter zu verändern.

Mit abnehmender Geschwindigkeit geht auch die Verdauung des Acidalbumins bei erhöhter Säureconcentration vor sich. Für das verdaute Acidalbumin ergibt sich bei

$$
\begin{array}{ccccc}
\% \mathrm{HCl} & 0,1 & 0,2 & 0,3 & 0,5 \\
& 100 & 94,5 & 84,7 & 76,1 .
\end{array}
$$

Die Ursache dieser Verzögerung der Verdauungsgeschwindigkeit liegt in der verdauungshemmenden Wirkung der höheren Säureconcentrationen, welche bereits S. $493 \mathrm{ff}$. hervorgehoben wurde, und diese ist begründet in der neben der Acidalbuminbildung einhergehenden Entstehung des von Meissner ${ }^{1}$ ) entdeckten, von Kühne und Chittenden ${ }^{2}$ ) Antialbumid benannten Parapeptons. Dieser Eiweisskörper, welcher dem Acidalbumin in vielen Stücken, namentlich in den Löslichkeitsverhältnissen, ähnlich ist, unterscheidet sich von ihm nach den Untersuchungen der genannten Autoren wieder mehrfach, nach Meissner aber namentlich durch seine Unverdaulichkeit.

Ich habe einen Versuch über die Bildung des unverdaulichen Eiweisskörpers angestellt, aus welchem sich ergeben hat, dass die Menge desselben zunimmt mit der Concentration der Säure und der Höhe der Tenıperatur. Das Eiweiss wurde zuerst mit der Säure

1) Meissner, a. a. 0. Bd. 7 S. 1. 1859 ; Bd. 8 S. 289.1860.

2) W. Kühne und R. H. Chittenden, Zeitschr. f. Biol. Bd. 19 S. 163 und 166.1883. 
behandelt und, nachdem die Säure wieder auf die Concentration von $0,2 \%$ gebracht worden war, der Einwirkung des Pepsins ausgesetzt.

Alle Proben enthielten gleich viel Eiweiss (annähernd $1 \mathrm{~g}$ in $100 \mathrm{ccm}$ ). Diese Proben wurden mit $0,2,0,3,0,4$ und $0,5 \% \mathrm{HCl}$ 30 Stunden auf $37,5^{\circ}$, die fünfte Probe mit $0,2 \% \mathrm{HCl} 30$ Stunden auf $55^{\circ}$, das Temperaturoptimum, erwärmt und die sechste Probe mit $0,2 \% \mathrm{HCl}$ ungefähr eine Stunde in siedendes Wasser getaucht. In den Proben mit $0,3-0,5 \% \mathrm{HCl}$ wurde die Säureconcentration durch Normallauge auf $0,2 \%$ herabgesetzt, diejenige Concentration, welche die anderen Proben gleich anfangs besassen. Die Pepsinmenge betrug in allen Proben gleich viel, die Verdauung wurde durch 16 Stunden bei $37,5^{\circ}$ vorgenommen.

Die Bestimmung der gebildeten secundären Albumose ergab folgende Linksdrehungen in Minuten:

$\begin{array}{lcccccc}\text { Probe } & 1 & 2 & 3 & 4 & 5 & 6 \\ \text { \% HCl anfangs } & 0,2 & 0,3 & 0,4 & 0,5 & 0,2 & 0,2 \\ 2 \alpha_{D} & 54,0 & 35,4 & 32,7 & 32,7 & 21,0 & 22,5\end{array}$

Der Versuch zeigt, dass das Parapepton auf Kosten des verdaulichen Acidalbumins zunimmt, woraus zu schliessen wäre, dass das Parapepton ein Zersetzungsproduct des Acidalbumins ist.

Die Frage nach der Abstammung der primären Albumose ist zur Zeit noch eine offene. In dieser Hinsicht ist Zweierlei möglich. Die primäre Albumose kann ein Verdauungsproduct des Acidalbumins sein, oder sie kann hervorgehen aus einer Spaltung des Albumins in zwei einander gleichwerthige Stoffe, in Acidalbumin und primäre Albumose, oder nach der Bezeichnungsweise von $K \ddot{u} h \mathrm{n} e$ in Anti- und Hemialbumose. Beide Ansichten haben ibre Vertreter gefunden, und für die Spaltungstheorie hat sich in letzter Zeit $\mathrm{Zunz} \mathrm{Z}^{1}$ ) mit grosser Entschiedenheit ausgesprochen.

$\mathrm{Zunz}$ hat für seine Behauptung zwei Gründe. Er hat beobachtet, dass das Auftreten des Acidalbumins stets von der Bildung von Albumose begleitet ist, und dass sogar zuweilen Spuren von primärer Albumose vor dem Acidalbumin auftreten. Die Thatsache, dass vor dem Acidalbumin schon Spuren von primärer Albumose nachzuweisen sind, widerspricht nach der Ansicht von $\mathrm{Zu} \mathrm{nz}$ besonders

1) E. Zunz, Zeitschr. f. physiol. Chemie Bd. 28 S. 161, 168 u. 169. 1899. 
schlagend der verbreiteten Annahme, nach welcher die primäre Albumose vom Acidalbumin abstammen soll. Den zweiten Grund findet $\mathrm{Zunz}$ in der Beobachtung von Goldschmidt ${ }^{1}$ ), wonach bei der Einwirkung von Säure auf krystallisirtes Serumalbumin Albumose zugleich mit dem Acidalbumin entstand, öfter schon, wo jede Spur von Acidalbumin vermisst wurde. Nach $\mathrm{Zunz}$ erfolgt die Bildung von Acidalbumin überhaupt durch Abspaltung von Albumosecomplexen vom Albumin.

Die Frage wäre sofort entschieden, wenn man wüsste, dass bei der Verdauung von reinem Acidalbumin überhaupt keine Albumose entstände; dann wäre die Bildung derselben nur auf eine Spaltung des Albumins zu beziehen. Aber das Gegentheil ist der Fall; wir selbst können nls Beweis hierfür den auf S. 482 erwähnten Versuch anführen, bei welchem wir eine Albumose, wie wir meinten, primäre, durch die Verdauung aus Acidalbumin erhielten. In jüngster Zeit habe ich den Verdauungsversuch mit reinem Acidalbumin wiederholt und, nach Entfernung eines Restes von Acidalbumin durch Neutralisiren, in der eingeengten Flussigkeit durch halbe Sättigung mit Ammonsulfat einen beträchtlichen klebrigen Niederschlag erhalten. Dieses Verhalten kennzeichnet aber nach $\mathrm{Pick}^{2}$ ) die primäre Albumose.

Wenn also (primäre) Albumose durch die Verdauung aus Acidalbumin entstehen kann, so wäre zu untersuchen, ob sich die von $\mathrm{Zunz}$ gemachte Wahrnehmung, nämlich, dass bei der Verdauung zeitweilig primäre Albumose ohne Acidalbumin auftreten kann, nicht auch aus einem Verdauungsvorgang erklären liesse. Die Angabe von $\mathrm{Zunz}$ ist richtig; unter den Beobachtungen ron Schütz finden sich zwei, in welchen gleichfalls kein Acidalbumin, aber primäre Albumose, und zwar in erheblicher Menge, angetroffen worden ist. Solche vereinzelte Wahrnehmungen bei Processen, bei denen nicht bloss eine einzige Reaction stattfindet, sondern mehrere neben und nacheinander einhergehen, sind aber nur mit grosser Vorsicht zu deuten. Berücksichtigt man in den einschlägigen Untersuchungen von $\mathrm{Schütz}$ diese einzelnen Fälle nicht bloss für sich, sondern im Zusammenhang mit. den übrigen Thatsachen, so gewinnt man einen Einblick in den wirklichen Hergang.

1) J. Goldschmidt, Ueber die Einwirkung von Sauren auf Eiweissstoffe. Dissertation. Strassburg 1898.

2) Ernst P. Pick, Zeitschr. f. physiol. Chemie Bd. 24 S. 246.1897. 
Die zwei Beobachtungen von $S c h u ̈ t z$, in welchen nur primäre Albumose vorkam und das Acidalbumin fehlte, betreffen die Versuche mit verschiedener Säureconcentration und mit verschiedenen Albuminmengen. Die zusammengehörigen Zahlen sind folgende:

Säureversuch

$\begin{array}{lcccc}\text { \% HCl } & 0,1 & 0,2 & 0,3 & 0,5 \\ \text { Verdautes Albumin } & 0,6099 & 0,7350 & 0,7567 & 0,7670 \\ \text { Acidalbumin } & 0 & 0,0407 & 0,1161 & 0,1835 \\ \text { I. Albumose } & 0,0845 & 0,0553 & 0,0668 & 0,0717\end{array}$

Albuminversuch

Albumin

$1 \quad 2$

Verdautes Albumin

Acidalbumin

$\begin{array}{cccc}0,6233 & 1,2113 & 1,7347 & 2,2170 \\ 0 & 0,0856 & 0,2602 & 0,4796 \\ 0,1737 & 0,2432 & 0,2635 & 0,1515\end{array}$

I. Albumose

$0,1737 \quad 0,2432$

0,2635

0,1515

Die vierte Zahl für die primäre Albumose, 0,1515, ist das Mittel aus zwei Bestimmungen, welche 0,2312 und 0,0713 ergaben, sie ist daher wahrscheinlich zu klein.

In den ersten Beobachtungen fehlte zwar das Acidalbumin, in den folgenden aber trat es auf, und zwar in Mengen, welche im Albuminversuch zunehmen mit der Menge des verdauten Albumins, bei dem Säureversuch mit der Steigerung der Säureconcentration und der dadureh bedingten Verdauungshemmung. Darnach erscheint die Annahme durchaus nicht gezwungen, dass auch in den ersten Versuchen Acidalbumin vorhanden war, dass es aber entsprechend seiner geringsten Menge, und, im Säureversuch, entsprechend der geringsten durch die Säure bedingten Verdauungshemmung, sogleich weiter verändert wurde. Man versteht so, wohin das zweite von $\mathrm{Zunz}$ vermisste vermeintliche Spaltungsstück des Albumins, das Acidalbumin, gekommen ist. So ist es auch begreiflich, wie in den frühesten Stadien der Verdauung neben dem Acidalbumin auch primäre Albumose angetroffen werden kann, das vorgefundene ist der Verdauung entgangen, während ein anderer Theil in primäre Albumose übergefübrt wurde.

Die zwei Pepsinversuche mit abnormem Verlauf, bei welchen entweder gar kein Acidalbumin aufgefunden wurde oder nur in Gegenwart der geringsten Pepsinmenge, fügen sich der gegebenen Erklärung über die Bildung der beiden Verdauungsproducte in natürlichster Weise. 
Zur Beurtheilung des zweiten Grundes für die Spaltungstheorie von $Z u n z$, welche dem gleichzeitigen Auftreten von Acidalbumin und primärer Albumose bei der Einwirkung von Säure allein auf das Albumin entnommen ist, stehen mir gleichfalls eigene Beobachtungen zur Verfügung.

Ich habe einmal zu einem anderen Zweck eine Ovalbuminlösung, welche in $50 \mathrm{ccm} 0,4989 \mathrm{~g}$ gewichtsanalytisch bestimmtes Albumin und $0,2 \% \mathrm{HCl}$ enthielt, längere Zeit auf $30^{\circ}$ gehalten und nach Ablauf bestimmter Zeitabschnitte in je $50 \mathrm{ccm}$ das gebildete Acidalbumin und das übrig gebliebene Albumin ermittelt. Dabei stellte sich heraus, dass die Summe beider Eiweisskörper kleiner war als die ursprüngliche Albuminmenge. Die Substanz, welche an der Summe fehlt, entspricht der primären Albumose. In der folgenden Tabelle habe ich die gefundenen Acidalbuminmengen und ferner die erwähnten Differenzen zusammengestellt, und zwar in absoluten Werthen und in Procenten des gebildeten Acidalbumins oder, was dasselbe ist, des zersetzten Albumins.

Stunden

1

2

4

8

12

24

Acidalbumin $\quad 0,1084$

$0,1562 \quad 0,1982$

0,2464

$0,2864 \quad 0,3148$

Differenz $\left\{\begin{array}{cc}g & 0,0119 \\ \% & -\end{array}\right.$

$0,0021-0,0013$

0,0027

0,0059

0,0082

Stunden

1,34

1,10

2,06

2,61

Acidalbumin
Differenz $\left\{\begin{array}{c}g \\ \%\end{array}\right.$

48

120

192

312

0,3519

0,3913

0,4110

0,4478

$0,0093 \quad 0,0167$

0,0193

0,0218

2,64

4,27

4,70

4,87

Aus der Berechnung der Procente habe ich die nach der ersten und vierten Stunde gefundenen Zahlen weggelassen, die erste, weil sie gegenüber den anderen zu gross, die zweite, weil sie negativ ist. Im Uebrigen zeigt sich aber, dass die in Procenten des verbrauchten Albumins ausgedrückte Differenz mit nur einer Ausnahme mit der Dauer des Versuches wächst; die Menge derjenigen Substanz, welche die Differenz verursacht, die primäre Albumose Goldschmidts, nimmt schneller zu als die Menge des Acidalbumins. Dieser Befund stimmt nun keineswegs zu der Annahme einer Spaltung des Albumins in Acidalbumin und primäre Albumose, denn dann müssten die Mengen der beiden Producte einander proportional sein, auf die verschiedenen Acidalbuminmengen müssten procentisch gleiche Mengen primärer Albumose entstehen. Die Erscheinung ist vielmehr so zu 
erklären, dass auch hier durch die Salzsäure allein das Acidalbumin zu Albumose zersetzt wird, langsamer als unter Mithülfe des Pepsins, eine Annahme, welche mit der Anschanung übereinstimnt, welche man von dem Wesen des Verdauungsprocesses überhaupt hegt.

Auf Grund dieser Thatsachen schliesse ich mich der Ansicht derjenigen an, welche die primäre Albumose als das erste Verdauungsproduct des Acidalbumins betrachten.

Die Mengen der überhaupt gebildeten primären Albumose fallen zusammen mit den auf S. 507 angeführten Mengen des verdauten Acidalbumins. Was dort von dem Abbau des Acidalbumins gesagt ist, gilt daher selbstrerständlich auch von der Bildung der primären Albumose.

Die Bildung der primären Albumose und ihr Verbrauch erfolgt unter gewissen Bedingungen in der Art, dass sich die Summen der Reste vom Acidalbumin und von der primären Albumose proportional der zu dem Versuch verwandten Albuminmenge verbalten. Ist diese Albuminmenge constant, so ergänzen sich die beiden Reste zu ejner Constanten. Diese Regel tritt da ein, wo die beiden die Verdaung bewirkenden Reagentien, die Säure und das Pepsin, unverändert bleiben. Das war der Fall in den Versuchen über den Einfluss der Temperatur, der Versuchsdauer und der Albuminmenge auf die Verdaungsgeschwindigkeit.

Die Zahlenbelege sind bereits im zweiten Abschnitt mitgetheilt worden, der Uebersichtlichkeit wegen fuhre ich sie hier noch einmal an. In der folgenden Zusammenstellung sind unter Acidalbumin und I. Albumose die in den Versuchen übrig gebliebenen Reste der beiden Substanzen zu verstehen.

\begin{tabular}{lcccc} 
Temperatur & $30^{\circ}$ & $35^{\circ}$ & $37,5^{\circ}$ & $40^{\circ}$ \\
Acidalbumin & 0,0563 & 0,0693 & 0,0705 & 0,0747 \\
I. Albumose & 0,0958 & 0,0742 & 0,0739 & 0,0787 \\
\hline Summe & 0,1521 & 0,1435 & 0,1444 & 0,1584
\end{tabular}

Die Resultate des bei $50^{\circ}$ angestellten Versuchs sind weggelassen, weil hier alles Albumin bereits verbraucht war.

\begin{tabular}{lccccc} 
Versuchsdauer & 1 & 4 & 9 & 16 & 25 St. \\
Acidalbumin & 0,3885 & 0,4721 & 0,3697 & 0,2832 & 0,2350 \\
I. Albumose & 0,0718 & 0,0938 & 0,1254 & 0,1787 & 0,2503 \\
\hline Summe & 0,4603 & 0,5659 & 0,4951 & 0,4619 & 0,4853
\end{tabular}

Unter der Annahme, dass die Acidalbuminmenge nach der vierten Stunde um $0,1 \mathrm{zu}$ gross bestimmt wurde, ordnet sich diese Summe gleichfalls in die Reihe ein. 
Ueber einige quantitative Verhaltnisse bei der Pepsinverdauung.

\begin{tabular}{ccccc} 
Albuminmenge & 1 & 2 & 3 & 4 \\
A cidalbumin & 0 & 0,0856 & 0,2602 & 0,4796 \\
I. Albumose & 0,1737 & 0,2432 & 0,2635 & 0,1515 \\
\hline Summe & 0,1737 & 0,3288 & 0,5237 & $(0,6311)$ \\
Verhaltniss berechnet & 0,1710 & 0,3420 & 0,5130 & $(0,6840)$
\end{tabular}

Die eine der Albumosezahlen bei der vierfachen Albuminmenge, 0,1515, ist das Mittel aus den beiden Einzelbestimmungen 0,2312 und 0,0718. Diese weichen so weit ron einander $a b$, dass das Mittel unmoglich richtig ist; die Zahl 0,0718 scheint um 0,1 zu klein zu sein, die Summe ist desshalb aus der Berechnung der Verhältnisszahl ausgeschlossen worden.

Die Ausgleichung der beiden Reste durch Wachsen des einen und Abnahme des anderen findet unter den verschiedenen Versuchsbedingungen in verschiedener Weise statt. Ein und derselbe Rest kann je nach den Umständen zu- oder abnehmen. Die Zunahme des Acidalbuminrestes zeigt eine Verminderung der Geschwindigkeit an, mit welcher die Menge der primären Albumose wächst, und umgekehrt, die Zunahme des Albumoserestes ist der Ausdruck einer Verringerung ihres Verbrauches.

Mit dem Ansteigen der Temperatur nimmt nun die Geschwindigkeit $a b$, mit welcher sich die primäre Albumose vermehrt, der Verbrauch an derselben aber zu; die Bildungsgesehwindigkeit der Albumose ist kleiner als die Geschwindigkeit ihres Verbrauches. Mit der Dauer des Versuchs findet das gerade Gegentheil statt, die Bildung der primären Albumose ist beschleunigt, ihr Verbrauch vermindert. Dagegen nimmit mit der Vermehrung des Albumins, wenigstens bis zur dreifachen Menge, sowohl die Bildung wie der Verbrauch der primären Albumose ab.

Bei den anderen Versuchen, bei welchen entweder die Säureconcentration orler die Pepsinmenge verändert wurde, standen die Summen der beiden Zwischenproducte nicht mehr in einem constanten Verhältniss zur Menge des dem Versuche unterworfenen Albumins.

In dem Säureversuch nahm die Bildungsgeschwindigkeit der primären Albumose mit der Steigerung der $S$ äureconcentration $a b$, offenbar wegen des Auftretens des unverdaulichen Parapeptons, der Verbrauch an Albumose blieb sich ziemlich gleich, und demgemäss wuchs die Summe der Reste.

\begin{tabular}{lcccc}
$\%$ HCl & 0,1 & 0,2 & 0,3 & 0,5 \\
Acidalbumin & 0 & 0,0407 & 0,1101 & 0,1835 \\
I. Albumose & 0,0845 & 0,0553 & 0,0668 & 0,0717 \\
\hline Summe & 0,0845 & 0,0960 & 0,1769 & 0,2552
\end{tabular}


Aus den beiden Pepsinversuchen mit normalem Verlauf ( $V$ und VI) ergibt sich, dass die Geschwindigkeit, mit welcher die primäre Albumose entsteht, mit der Vermehrung des Pepsins beschleunigt wird, ihre Zersetzung aber in geringerem Grade abnimmt, derart jedoch, dass die Summen gleichfalls abnehmen. In den Pepsinversuchen mit abnormem Verlauf (VII und VIII) ist schon bei den geringeren Pepsinmengen so viel primäre Albumose entstanden, als überhaupt entstehen konnte, und die nothwendige Folge davon ist, dass um so mehr verbraucht wird, je mehr Pepsin zugegen ist.

$\begin{array}{lcccc}\text { V. Pepsin } & 1 & 4 & 9 & 16 \\ \text { Acidalbumin } & 0,6419 & 0,3484 & 0,1258 & 0,0348 \\ \text { I. Albumose } & 0,0223 & 0,0067 & 0,0579 & 0,0834 \\ \text { Summe } & 0,6642 & 0,3551 & 0,1837 & 0,1182\end{array}$

VI. Pepsin

\begin{tabular}{lllll} 
Acidalbumin & 0,3410 & 0,2269 & 0,1117 & 0,0442 \\
I. Albumose & 0,0204 & 0,0771 & 0,1015 & 0,0906 \\
\hline Summe & 0,3614 & 0,3040 & 0,2132 & 0,1348
\end{tabular}

Die in den Versuchen bestimmte primäre Albumose ist derjenige Theil der überhaupt gebildeten, welcher bei der Ueberführung der primären Albumose in die secundäre übrig geblieben ist. Der Bruchtheil, welchen die secundäre Albumose von der Summe beider Albumosen ausmacht, bildet ein Maass für die Geschwindigkeit, mit welcher die secundäre Albumose aus der primären entsteht. Die folgende Zusammenstellung gibt eine Uebersicht über diese Bruchtheile. Von diesen Verhältnisszahlen sind einige mangelhaft und diese aus den im II. Abschnitt angeführten Gründen aus der folgenden Zusammenstellung ausgeschieden.

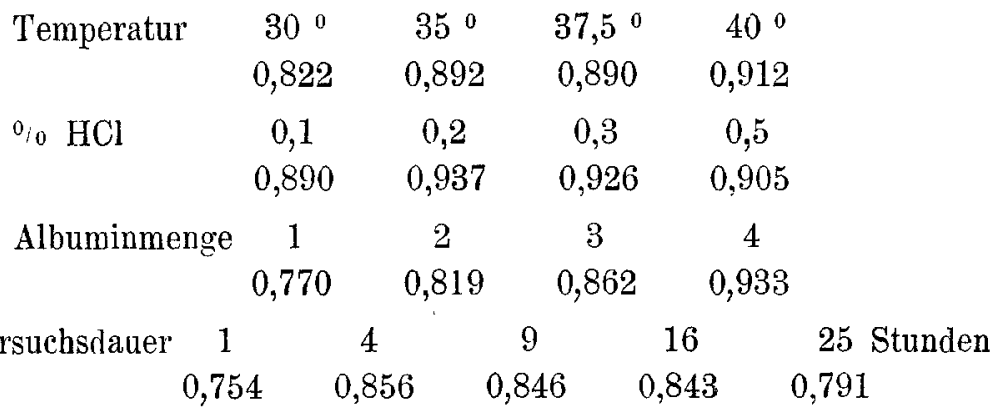

Das Mittel aller Zahlen beträgt 0,818 , das der drei mittleren 0,848 . 
Ueber einige quantitative Verhàltnisse bei der Pepsinverdauung.

$\begin{array}{ccccc}\text { Pepsin } & 1 & 4 & 9 & 16 \\ \text { V } & 0,933 & 0,985 & 0,915 & 0,898\end{array}$

Das Mittel aus allen Zahlen $=0,933$, das aus der ersten und den zwei letzten $=0,915$.

$\begin{array}{rcccc}\text { Pepsin } & 1 & 9 & 25 & 49 \\ \text { VII } & 0,899 & 0,967 & 0,987 & 0,985 \\ \text { VIII } & 0,862 & 0,889 & 0,847 & 0,939\end{array}$

Das Mittel der Zahlen von VII beträgt 0,960 , von VIII 0,884 .

Nach diesen Zahlen scheint es, dass weder durch die Vermehrung des Pepsins, noch durch die Verlängerung der Versuchsdauer die Geschwindigkeit, mit welcher die primäre Albumose in die secundäre übergeht, geändert wurde, oder doch nur in geringfügiger Weise. In diesem Falle wäre die Geschwindigkeit, mit welcher die secundäre Albumose gebildet wird, direct abhängig von der Geschwindigkeit der Bildung der primären Albumose oder, was dasselbe ist, abhängig von der Geschwindigkeit, mit welcher das Acidalbumin verbraucht wird. Es wäre dann zu erwarten, dass sich in diesen Versuchen die Mengen des verbrauchten Acidalbumins verhielten wie die Mengen der secundären Albumose. Von einem solchen Vergleich ist wegen der Fehler, mit welchen die Bestimmungen behaftet sind, eine grosse Uebereinstimmung der Berechnung mit dem Befunde nicht zu erwarten; man wird sich zufrieden geben müssen, wenn der Vergleich nur im Sinne der Voraussetzung ausfällt.

Die secund äre Albumose entsteht nach S. $497 \mathrm{ff}$. proportional der Wurzel aus den Pepsinmengen; dasselbe Verhältniss sollten die Mengen der gebildeten primären Albumose darbieten. Der Pepsinversuch $\mathrm{V}$, der einzige zu dem Vergleich taugliche, hat ergeben an entstandener primärer Albumose:

$\begin{array}{ccccc}\text { Pepsin } & 1 & 4 & 9 & 16 \\ \text { gefunden } & 0,1180 & 0,4086 & 0,6095 & 0,7347 \\ \text { berechnet } & 0,1871 & 0,3742 & 0,5612 & 0,7483\end{array}$

Die Versuchsdauer beschleunigt die Bildung der secundären Albumose in der Weise, dass sich die Mengen der secundären Albumose bei geringer Geschwindigkeit verhalten wie die Wurzeln aus den Zeiten; bei grosser Geschwindigkeit dagegen entsteht anfangs mehr, später weniger secundäre Albumose, als sich nach dem Wurzelverhältnisse berechnet. In dem Verdauungsversuch über den Einfluss der Versuchsdauer wurde an gebildeter primärer Albumose nach 
E. Schutz und Huppert:

$\begin{array}{cccccc}\text { Stunden } & 1 & 4 & 9 & 16 & 25 \\ \text { gefunden } & 0,2968 & 0,5431 & 0,7622 & 0,9353 & 1,0166,\end{array}$ nach dem Wurzelverhältniss

$\begin{array}{llllll}\text { berechnet } \quad 0,2369 & 0,4739 & 0,7108 & 0,9477 & 1,1847 \text {. }\end{array}$

Die Bildung der primären Albumose geht also, wie die Bildung der secundären Albumose nach der zweiten Regel, so vor sich, dass sie anfangs die nach dem Wurzelverhältniss berechnete Menge überholt, später hinter ihr zurückbleibt. Die Annahme von den numerischen Beziehungen der beiden Albumosen zu einander hat also wenigstens eine grosse Wahrscheinlichkeit für sich.

Aus den übrigen Versuchen hat sich eine derartige Abhängigkeit der Bildung der secundären Albumose von der Bildung der primären nicht ergeben.

Mit der Vermehrung der Albuminmenge beschleunigt sich die Geschwindigkeit, mit welcher die primäre Albumose in die secundäre übergeht; gleichwohl entsteht die secundäre Albumose in Mengen, welche der zu dem Versuche verwendeten Albuminmenge proportional sind. Die Beschleunigung, mit welcher die secundäre Albumose entsteht, wird aber ausgeglichen durch die Verzögerung in der Bildung der primären Albumose. Von dieser entstehen bei Albuminmenge

$$
\begin{array}{cccc}
1 & 2 & 3 & 4 \\
0,6223 & 1,1257 & 1,4745 & 1,7374,
\end{array}
$$

also keineswegs Mengen, welche den Albuminmengen proportional sind. Theilt man diese Zahlen durch die Albuminmengen, so verhalten sich die Quotienten zu den Zahlen, welche die Bildungsgeschwindigkeit der secundären Albumose ausdrücken, nämlich

$$
\begin{array}{llll}
0,770 & 0,819 & 0,862 & 0,933
\end{array}
$$

umgekehrt proportional. Bildet man aus den zusammengelörenden Zahlen beider Reihen die Producte, so erhält man

$$
4,79 \quad 9,22 \quad 12,71 \quad 16,21,
$$

und diese verhalten sich annähernd wie die Albuminmengen, nämlich wie

$$
4,29 \quad 8,59 \quad 12,88 \quad 17,17,
$$

oder, wenn das zweite Product $(0,819)$ aus der Berechnung weggelassen wird, wie

$$
4,21 \quad(8,43) \quad 12,64 \quad 16,86 \text {. }
$$

Die Uebereinstimmung ist so gross, als man sie nach den nicht ganz sicheren Zahlen der Tabellen erwarten kann. 
Die Zahlen, welche die Geschwindigkeit der Zersetzung der primären Albumose unter dem Einflusse verschiedener Säureconcentration angeben, stehen im Einklang mit der Bildung der secundären Albumose im Verdauungsversuche; bei $0,2 \% \mathrm{HCl}$ sind sie grösser als bei $0,1 \%$, bei $0,3 \%$ so gut als gleich den bei $0,2 \%$, und bei $0,5 \%$ fallen sie. In demselben Sinne verbalten sich die Mengen der gebildeten primären Albumose.

Aus den Verhältnisszahlen für die Temperatur, welche im Gange des Versuchs grösser werden, könnte man folgern, dass mit dem Ansteigen der Temperatur die Ueberführung der primären Albumose in die secundäre beschleunigt wird.

Aus den Tabellen von Schütz lässt sich die Menge der gebildeten secundären Albumose ableiten, wenn man von der überhaupt gebildeten primären Albumose (der Menge des verbrauchten Acidalbumins) die übrig gebliebene primäre Albumose abzieht. Wegen der Häufung der Bestimmungsfehler fallen diese Zahlen nicht sehr richtig aus, aber sie zeigen doch in der überwiegenden Zahl der Einzelbeobachtungen eine Proportionalität zu den Ergebnissen der directen Bestimmung der secundären Albumose, welche ungefähr ebenso schwanken wie in den Tabellen das Verhältniss zwischen Summe der Verdauungsproducte und der Menge des verdauten Albumins.

Begreiflicherweise hat die directe Bestimmung der secundären Albumose richtigere Werthe ergeben. Die bei dieser gewonnenen Resultate lassen sich in einen einheitlichen Ausdruck zusammenfassen. Innerhalb gewisser Bedingungen entsteht die secundäre Albumose einfach proportional der Albuminmenge und proportional der Quadratwurzel aus der Versuchsdauer, der Pepsinmenge und der Säureconcentration. Die Bedingungen, unter denen diese Regel zutrifft, sind für die Versuchsdauer ein mässig schneller Verlauf der Reaction und für die Säure eine $0,2 \%$ nicht übersteigende Concentration. Bezeichnet man die secundäre Albumose mit $S$, die Albuminmenge mit $A$, die Pepsinmenge mit $p$, die Versuchsdauer mit $t$ und die Säureconcentration mit $s$, so wird die Geschwindigkeit, mit welcher die secundäre Albumose entsteht, ausgedrückt durch

$$
S=k A \sqrt{p t s}
$$

worin $h_{b}$ die Geschwindigkeitsconstante bedeutet.

Setzt man je zwei unter dem Wurzelzeichen stehende Grössen $=1$, so kommt nur die eine übrig bleibende nach dem Wurzel- 
verbältnisse zur Geltung, und wird nur eine der Grössen $=1$, die beiden anderen nach ihren Producten. Lässt man, ausser der Albuminmenge, von den drei Grössen die eine, z. B. die Säureconcentration unverändert und verwendet von $p$ das $m$-fache, so bleibt der Werth von $S$ unverändert, wenn man von $t$ den $m$-ten Theil nimmt. Diese aus der Formel abgeleitete Folgerung findet in den Thatsachen ihre Bestätigung.

Es wurden gleiche Mengen Eiweiss bei $37,5^{\circ}$ mit $0,25 \% \mathrm{HCl}$ verdaut und gefunden bei

$$
\begin{array}{ccccc}
\text { Stunden } & 4 & 8 & 12 & 16 \\
\text { und cem Pepsin } & 12 & 6 & 4 & 3 \\
2 \alpha_{D}= & -50,3^{\prime} & -50,2^{\prime} & -49,2^{\prime} & -50,1^{\prime} .
\end{array}
$$

Von dieser gegenseitigen Vertretung der einen Grösse durch die anderen wurde im zweiten Säureversuch S. 491 und in dem vierten Volumversuch S. 503 Gebrauch gemacht.

\section{Die Bestimmung der relativen Pepsinmenge.}

Die mangelhafte Kenntniss, welche wir vom Pepsin selbst besitzen, hat zur Folge, dass alle Methoden der quantitativen Pepsinbestimmung nur in der Ermittelung der Reactionsgeschwindigkeit bestehen können. Aus demselben Grunde ist das Maass für die Pepsinmenge, die gewählte Einheit, eine willkürliche.

Je nach dem befolgten Princip lassen sich folgende drei Arten der Pepsinbestimmung unterscheiden.

Bei dem Verfahren vo n Schütz ${ }^{1}$ ) bildet diejenige Menge der secundären Albumose das Maass für das Pepsin, welche unter bestimmten Bedingungen gebildet wird; es soll in $100 \mathrm{ccm}$ Gesammtlösung $1 \mathrm{~g}$ gelöstes Albumin mit 0,25-0,30\% $\mathrm{HCl} 16$ Stunden bei $37,5^{\circ}$ der Verdauung unterworfen werden. Zur Isolirung der secundären Albumose wird die Verdauungsmischung mit Ferriacetat ausgefällt und die in Lösung bleibende Albumose polarimetrisch bestimmt. Um die Polarisationsfehler kleiner zu machen, wird die Albumoselösung nach dem S. 483 beschriebenen Verfahren von $250 \mathrm{ccm}$ auf 50 eingedampft und die Polarisation im Zwei-Decimeterrohr vorgenommen. Die Pepsinmenge ergibt sich aus der Regel, dass sich die Mengen der secundären Albumose verhalten wie die Wurzeln

1) E. Schütz, Zeitschr. f. physiol. Chemie Bd. 9 S. 577. 1885. 
aus den Pepsinmengen. Nach den auf S. $497 \mathrm{ff}$. angeführten Belegen ist diese Regel sicher begründet; sie versagt nur, wenn die Drehung 100 Minuten übersteigt.

Einen Vorzug besitzt das Verfahren von Schütz durch die Aufstellung einer Pepsineinheit; darunter wird diejenige Pepsinmenge verstanden, welche unter den angegebenen Bedingungen $1 \mathrm{~g}$ secundäre Albumose zu bilden vermag. Damit ist ein fixes überall anwendbares Maass für die Pepsinmenge gegeben. Die Einheit macht eine constante Vergleichslösung, auf welche die Bestimmungen zu beziehen wären, entbehrlich, ein Umstand, der um so böher anzuschlagen ist, als eine Pepsinlösung beim Aufbewahren an Wirksamkeit einbüsst.

Die beobachtete (Links-)Drehung sei $m^{0}$. Da die Lósung fünf Mal so concentrirt ist als die ursprungliche und im 2-Decimeterrohr beobachtet wurde, so betrảgt die Drehung der ursprünglichen Lösung nur $\frac{m^{0}}{10}$. Die specifische (Links-)Drehung der secundaren Albumose $=41,33^{\circ}$, d. h. so stark würde eine Losung drehen, welche in $100 \mathrm{ccm} 100 \mathrm{~g}$ der Albumose enthielte. Eine $\frac{m^{0}}{10}$ drehende Losung wüde demnach in $100 \mathrm{ccm} \frac{100}{41,33} \frac{m}{10}=\frac{m}{4,133} \mathrm{~g}$ secundare Albumose enthalten. Die ursprungliche Lösung betrug aber $250 \mathrm{ccm}$, und in dieser wären also enthalten $\frac{2,5 m}{4,133}=\frac{m}{4 \times 0,4133}=\frac{m}{1,653} \mathrm{~g}$, oder, wenn die beobachtete Drehung in Minuten ausgedrückt wird, $\frac{m}{99,2} \mathrm{~g}$. Bezeichnet man mit $P$ die Anzahl der Pepsineinheiten, mit $p$ die Anzahl der ccm Pepsinlosung, so ergibt sich die Anzahl der im ccm enthaltenen Pepsineinheiten aus $P=\frac{1}{p}\left(\frac{m}{99,2}\right)^{2}$, wenn die Drehung in Minuten bestimmt wurde. Fúr diese Formel ist die richtige specifische Drehung benutzt.

Zur Ausführung der Bestimmung ist allerdings ein Polarimeter erforderlich, aber diese gehören doch zu den nothwendigen Erfordernissen der internen Kliniken, und für die in Rede stehende Untersuchung genügt einer der billigen Halbschattenapparate, mit welchen sich der Zucker noch auf Zehntelprocente bestimmen lässt; es entspricht aber $0,1^{\%}$ Traubenzucker $0,0525^{\circ}=3,15^{\prime}$ oder 0,001 Pepsineinheiten. Die Apparate sind auch für die hier erforderliche Linksdrehung eingerichtet.

Will man nach diesem Verfahren den Pepsingehalt eines Magensaftes bestimmen, so hat man zu berücksichtigen, dass dieser nicht 
bloss secundäre Albumose enthalten kann, sondern aucb noch andere Eiweisssubstanz, welche während des Versuchs in secundäre Albumose übergehen könnte. Um diese Grösse würde die Bestimmung falsch ausfallen. Man hat daher zunächst den Saft rom suspendirten Eiweiss zu befreien dadurch, dass man ihn durch ein engmaschiges Gewebe presst. Ihn zu filtriren ist unzweckmässig, weil der Schleim, an welchem Pepsin haftet, nur sehr unvollkommen durch das Papier geht. Es werden dann zwei gleich grosse Volumina des Saftes zu dem Versuch verwendet; mit dem einen verdaut man $1 \mathrm{~g}$ Eiweiss, das andere digerirt man in $100 \mathrm{ccm}$ bei derselben Säureconcentration für sich. In beiden Proben wird die secundäre Albumose bestimmt und die im blinden Versuch gefundene Menge von der im Verdauungsversuch ermittelten abgezogen. Enthielte der Magensaft rechtsdrehendes Kohlenhydrat, so würde zu wenig secundäre Albumose gefunden; aber dieser Fehler wird gleichfalls durch den blinden Versuch beseitigt.

Dem Verfahren von $\mathrm{Br}_{\text {ücke }}{ }^{1}$ ) liegt die keineswegs selbstverständliche Voraussetzung zu Grunde, dass unter sonst gleichen Bedingungen die Geschwindigkeit, mit welcher eine Fibrinflocke oder ein Stück coagulirtes Eiereiweiss gelöst wird, direct proportional ist der Concentration der Pepsinlösung (der relativen Pepsinmenge) und umgekehrt proportional der Zeit.

Die Reactionsgeschwindigkeit, mit welcher das Pepsin gemessen wird, ist hier eine andere als bei der Methode von Schütz. Bei dem Verfahren von Schütz nimmt diese Geschwindigkeit mit der Dauer des Versuchs ab, während sie bei dem Verfahren von Brúcke als gleichbleibend angenommen wird. Der Grund des Unterschiedes ist leicht ersichtlich. In dem Verdaungsversuch von Schütz befindet sich die ganze Eiweissmenge von Anfang an in Lösung (homogenes System), im Verlaufe des Versuchs nimmt die Menge des Verdaungsobjects mehr und mehr ab, und damit verringert sich, in der Zeiteinheit, auch die Menge des Verdauungsproducts. Die Versuchsmischung von $\mathrm{Brücke}$ bildet dagegen ein heterogenes System, es befindet sich in ihr ein Vorrath von festem Eiweiss, welches durch die Einwirkung der Salzsäure in Acidalbumin übergeht. Verdaut wird aber nur das in Lösung befindliche Acidalbumin.

1) Brù cke, Sitzungsber. der k. Akad. d. Wissensch., mathem. - naturw. Classe Bd. 37 S. 147. 1859. 
In dem Naasse, als dieses aus der Lösung versehwindet, in demselben Maasse geht Acidalbumin von dem Vorrath in Lösung, und desshalb kann die Verdauungsgeschwindigkeit, so lange noch ungelöstes Eiweiss vorhanden ist, in jedem Zeitpunkt dieselbe sein.

Aus der Abnahme des Verdauungsobjects in dem Versuch von Schütz erklärt sich dann auch, warum die secundäre Albumose nicht proportional der verwendeten Pepsinmenge, sondern in geringerer Menge entsteht. Wird dagegen das verbrauchte Fiweiss im Verlauf des Versuchs fortwährend ersetzt, so lässt sich erwarten, dass sich die gebildete secundäre Albumose proportional der Pepsinmenge verhält, wie es bei dem Verfahren von B rücke vorausgesetzt wird.

Folgende von mir über die Verdaulichkeit des Acidalbumins angestellte Versuche sprechen für die Richtigkeit dieser Voraussetzung. Es wurden zwei Versuchsreihen angestellt. In der einen Reihe befand sich das Acidalbumin in Lösung, und die Mengen der gebildeten secundären Albumose verhielten sich nahezu wie die Wurzeln aus den Pepsinmengen. In der zweiten Reihe wurde das Acidalbumin in der Form eines dünnen Kleisters angewendet und war am Ende der Versuche noch nicht verbraucht; hier war die Menge der gebildeten Albumose direct proportional der Pepsinmenge. Das Zahlenergebniss war folgendes.

Die angegebenen Werthe sind Linksdrehungen in Minuten.

1. Gelóstes Acidalbumin, Saureconcentration $0,222 \%$, Temperatur $37,5^{\circ}$, Versuchsdauer 16 Stunden.

\begin{tabular}{|c|c|c|c|c|c|c|}
\hline nmenge & & 1 & 2 & 3 & 4 & 5 \\
\hline & & & 2 & 27,15 & 30,15 & 32 \\
\hline & berec & 15,75 & 22,02 & 26,97 & 31,14 & 34,8 \\
\hline
\end{tabular}

2. Suspendirtes Acidalbumin, wenig Pepsin, 0,213\% HCl, 37,50, 16 Std.

II. Albumose $\left\{\begin{array}{lccccc}\text { gefunden } & 1 & 2 & 3 & 4 & 5 \\ \text { berechnet } & 7,76 & 15,61 & 21,93 & 31,11 & 36,50 \\ \text { Ifinmenge } & 15,19 & 22,78 & 30,97 & 37,97\end{array}\right.$

Darnach scheint das Verfahren von Brücke im Princip richtig zu sein, wenn man die Menge der secundären Albumose als Maass für das Pepsin annimmt, wiewohl doch erst Versuche mit coagulirtem Eiweiss die Entscheidung geben können. Bei dem Verfahren von Brücke wird aber dje Lösungsgeschwindigkeit der Verdauungsgeschwindigkeit gleichgesetzt, was nicht ohne Weiteres als richtig zugegeben werden kaun; denn die unter Mitwirkung von Pepsin erhaltene Lösung enthält nicht bloss secundäre Albumose, sondern auch Acidalbumin und primäre Albumose. 
Der Grad, mit welchem die nach dem Brü cke'schen Verfahren erbaltenen Resultate mit der Theorie übereinstimmen, hängt von der Versuchsanordnung ab. Gegen diese lassen sich aber von vornherein schwere Bedenken geltend machen. Eine wesentliche Schwierigkeit bietet die Auswahl der Fibrinflocken dar, welche nicht bloss gleich gross sein sollen, sondern auch die gleiche Beschaffenheit der Oberfläche und die gleiche Dichte besitzen müssen. Der Einfluss eines ungleichen Gehaltes an Fett liesse sich durch Entfetten des Fibrins beseitigen. Ein Bedenken könnte man ferner darin finden, dass während der Verdauung die Oberfläche der Fibrinflocke kleiner wird und dass desshalb die Verdauungsgeschwindigkeit abnehmen müsste; aber das Fibrin wird schnell in Acidalbumin verwandelt, und dieser Vorrath reicht lange aus, auch wenn die Flocke klein geworden ist, das aus der Lösung verschwindende zu ersetzen. Ein weiterer grosser Uebelstand besteht darin, dass man die Zeit nicht verpassen darf, bei welcher die Lösung des Materials gerade eingetreten ist, und es wäre dazu eigentlich eine ununterbrochene Beobachtung erforderlich; das liesse sich wohl noch möglich machen, wenn der Versuch nicht lang dauerte, aber nach Brücke's Erfahrungen werden ganz unbrauchbare Resultate erhalten, wenn die Zeit, innerhalb welcher die Lösung erfolgt, nur 20-45 Minuten beträgt.

Was aber das Verfahren von Brücke leistet, ergiht sich aus

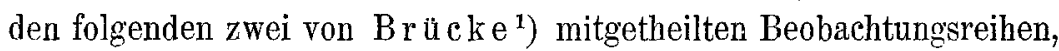
in welchen die erste Zeile die relative Pepsinmenge angibt, die zweite die Zeit, binnen welcher die Fibrinflocken gelöst wurden.

1. Pepsin 1

2

$\begin{array}{llll}4 & 8 & 16 & 32\end{array}$

Stunden

$\begin{array}{lcccc}\text { vor } 20 & \text { zwischen } 7 & \text { u. } 20 & 7 & 31 / 2 \\ \text { 2. Pepsin } & 1 & 2 & 4 & 8 \text { u. } 16 \\ \quad \text { Stunden } & \text { nach } 3 & 3 & 2 & \text { vor } 1 .\end{array}$

Entsprächen die Resultate der Theorie, so müssten die Producte je zweier zu einander gehörigen, die Zeit und die Pepsinmenge betreffenden Zahlen gleich sein. Diese Forderung trifft jedoch nur ausnahmsweise zu.

Einen höheren Grad von Genauigkeit als das Brücke'sche Verfahren dürften solche auf demselben Princip beruhende erreichen, bei welchen die Menge der in Lösung gegangenen Substanz durch Bestimmen des übrig gebliebenen Restes ermittelt wird. In eigen-

1) Brücke, a. a. 0. S. 131 . 
thümlicher Weise geschieht dies in dem von $\mathrm{Paw} 10 \mathrm{w}^{1}$ ) warm empfohlenen Verfahren von $\mathrm{Mett}^{2}$ ). Samojloff $\mathrm{f}^{3}$ ) gibt eine ausführliche Beschreibung des Verfahrens.

Es wird Eiereiweiss in $1-2 \mathrm{~mm}$ weiten Glasröhrchen bei $95^{\circ}$ coagulirt, bei dieser Temperatur desshalb, weil nur so ein lückenfreies Coagulum entsteht. Die Röhrchen werden in $1-1,5 \mathrm{~cm}$ lange Stücke zerschnitten und bei $37-38^{\circ}$ der Einwirkung der Verdauungsflüssigkeiten ausgesetzt, deren Gehalt an Enzym bestimmt werden soll. Die Lösung des Eiweisses erfolgt an beiden Enden. Nach Ablauf einer bestimmten Frist (gewöhnlich 10 Stunden) bestimmt man die Länge des unverdaut gebliebenen Eiweisscylinders und die Länge des Glasrohrs und drückt die Länge des verdauten Stücks in Millimetern und deren Bruchtheilen aus.

Nach Samojl off verläuft die Verdauung wenigstens innerhalb der ersten 10 Stunden (ziemlich) proportional der Versuchsdauer, die Länge des verdauten Stücks darf an jeder Seite höchstens $6-7 \mathrm{~mm}$ betragen, sonst versagt die Regel. Für die Beziehungen der Pepsinmenge zur Verdauungsgeschwindigkeit hat Borissow angegeben, dass sich die Pepsinmengen verhalten wie die Quadrate der Verdauungsgeschwindigkeiten, d. h. wie die Quadrate der Millimeter Eiweisssäule, welche in gleicher Zeit von den Verdauungssäften gelöst werden. Die Geschwindigkeit würde also auch hier der Regel von Schütz folgen.

Die Publication von Borissow ist mir nicht zugänglich, aber S a mojl off hat selbst solche Bestimmungen ausgeführt; aus diesen ergibt sich jedoch nur eine mangelhafte Uebereinstimmung der Beobachtung mit der Rechnung. Die Abweichungen sind derart, dass man aus den Beobachtungen ebenso gut ein anderes Verhältniss ableiten kann, nämlich dass sich die Pepsinmengen verhalten wie die Kuben der Verdauungsgeschwindigkeiten. Man kann das Verhältniss, um es der Regel von Schütz conform zu machen, auch so ausdrücken, dass sich die Längen des verdauten Eiweisscylinders verhalten wie die Quadratwurzeln (oder wie die Kubikwurzeln) aus der Concentration der Pepsinlösung. Samojl off hat die verschiedenen Concentrationen hergestellt durch Verdünnen von natürlichem Magen-

1) J. P. Paw low, Die Arbeit der Verdauungsdrüsen 1898 S. :31.

2) S. G. Mett, Du Bois' Archiv 1894 S. 68.

3) A. Samojloff, Arch. des sciences biologiques t. 2 p. 699.1893. 
saft mit Salzsäure derselben Concentration. $O b$ er zu den Versuchen gleiche Volumina angewendet hat, ist aus der Abhandlung nicht ersichtlich; nach Mett ${ }^{1}$ ) kommt es darauf nicht an.

Um zu zeigen, in welchem Grade die Beobachtung mit der Rechnung übereinstimmt, führe ich zwei von Samojl off ausgeführte Bestimmungen an, bei welchen ich die Rechnung nach der Quadratund nach der Kubikwurzel vorgenommen habe.

1. Pepsinmengen $\begin{array}{lllllll}64 & 32 & 16 & 8 & 4 & 2 & 1\end{array}$ $\begin{array}{llllllll}\mathrm{mm} \text { verdaut } \quad 6,68 & 5,12 & 3,98 & 3,08 & 2,32 & 1,75 & 1,37\end{array}$ $\begin{array}{llllllll}\text { Quadratwurzel } & 7,81 & 5,32 & 3,90 & 2,76 & 1,94 & 1,38 & 0,98\end{array}$ $\begin{array}{llllllll}\text { Kubikwurzel } & 6,25 & 4,97 & 3,92 & 3,12 & 2,48 & 1,97 & 1,56\end{array}$

2. Pepsinmengen $\begin{array}{llllll}32 & 16 & 8 & 4 & 2 & 1\end{array}$ $\mathrm{mm}$ verdaut $\quad 6,72 \quad 5,33 \quad 4,20 \quad 3,07 \quad 2,01 \quad 1,69$ Quadratwurzel $\quad 7,08 \quad 5,45 \quad 3,84 \quad 2,72 \quad 1,92 \quad 1,36$ Kubikwurzel $\quad 6,36 \quad 5,04 \quad 4,00 \quad 3,18 \quad 2,52 \quad 2,00$.

Man wird hieraus erkennen, dass das Verfahren von Mett zu genauen Bestimmungen der relativen Pepsinmenge nicht geeignet ist.

1) Mett, a. a. O. S. 69. 